\title{
Multiple Redox Modes in the Reversible Lithiation of High-Capacity, Peierls-Distorted Vanadium Sulfide
}

Sylvia Britto, Michal Leskes, Xiao Hua, Claire-Alice Hébert, ${ }^{\S}$ Hyeon Suk Shin, ${ }^{*}$ Simon Clarke, ${ }^{\dagger \dagger}$ Olaf Borkiewicz, ${ }^{+}$Karena W. Chapman, ${ }^{+}$Ram Seshadri, ${ }^{\ddagger}$ Jaephil Cho ${ }^{\dagger}$ and Clare P. Grey ${ }^{* @}$

*Department of Chemistry, Lensfield Road, University of Cambridge, Cambridge CB2 1EW, United Kingdom

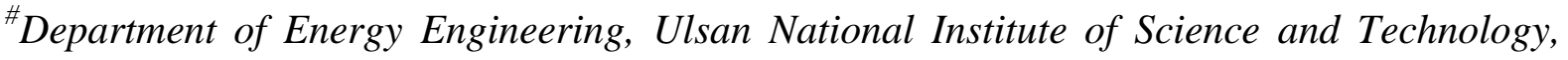
Korea

${ }^{\S}$ College of Creative Studies, University of California, Santa Barbara, CA 93106, USA

${ }^{+} X$-ray Science Division, Advanced Photon Source, Argonne National Laboratory, Illinois 60439, USA

${ }^{\ddagger}$ Mitsubishi Chemicals Center for Advanced Materials Research Laboratory, University of California, Santa Barbara, CA 93106, USA

${ }^{\dagger}$ Nano Energy Materials Lab, Interdisciplinary School of Green Energy, Ulsan National Institute of Science and Technology, Korea

${ }^{\dagger}$ Department of Chemistry, University of Oxford, Inorganic Chemistry Laboratory, South Parks Road, Oxford, OX1 3QR, UK.

${ }^{\circledR}$ Corresponding author, cpg27@cam.ac.uk

Keywords: lithium-ion battery, conversion mechanism, peierls distortion 


\begin{abstract}
Vanadium sulfide $\mathrm{VS}_{4}$ in the patronite mineral structure, is a linear chain compound comprising vanadium atoms coordinated by disulfide anions $\left[\mathrm{S}_{2}\right]{ }^{2-} \cdot{ }^{51} \mathrm{~V}$ NMR shows that the material, despite having $\mathrm{V}$ formally in the $\mathrm{d}^{1}$ configuration, is diamagnetic, suggesting potential dimerization through metal-metal bonding associated with a Peierls distortion of the linear chains. This is supported by density functional calculations, and is also consistent with the observed alternation in $\mathrm{V}-\mathrm{V}$ distances of $2.8 \AA$ and $3.2 \AA$ along the chains. Partial lithiation results in reduction of the disulfide ions to sulfide $\mathrm{S}^{2-}$, including via an internal redox process whereby an electron from $\mathrm{V}^{4+}$ is transferred to $\left[\mathrm{S}_{2}\right]^{2-}$ resulting in oxidation of $\mathrm{V}^{4+}$ to $\mathrm{V}^{5+}$ and reduction of the $\left[\mathrm{S}_{2}\right]^{2-}$ to $\mathrm{S}^{2-}$ to form $\mathrm{Li}_{3} \mathrm{VS}_{4}$ containing tetrahedral $\left[\mathrm{VS}_{4}\right]^{3-}$ anions. On further lithiation this is followed by reduction of the $\mathrm{V}^{5+}$ in $\mathrm{Li}_{3} \mathrm{VS}_{4}$ to form $\mathrm{Li}_{3+\mathrm{x}} \mathrm{VS}_{4}(\mathrm{x}=0.5-1)$, a mixed valent $\mathrm{V}^{4+} / \mathrm{V}^{5+}$ system. Eventually reduction to $\mathrm{Li}_{2} \mathrm{~S}$ plus elemental V occurs. Despite the complex redox processes involving both the cation and the anion occurring in this material, the system is found to be partially reversible between 0 and 3 $\mathrm{V}$. The unusual redox processes in this system are elucidated using a suite of short range characterization tools including ${ }^{51} \mathrm{~V}$ Nuclear Magnetic Resonance spectroscopy (NMR), S Kedge X-ray Absorption Near Edge Spectroscopy (XANES) and Pair Distribution Function (PDF) Analysis of X-ray data.
\end{abstract}




\section{INTRODUCTION}

The reversible reactions of insertion electrodes such as $\mathrm{LiCoO}_{2}{ }^{1}$ and graphite ${ }^{2}$ in rechargeable $\mathrm{Li}$ ion batteries are frequently based on topotactic reactions where the layered structure of the host remains essentially intact as $\mathrm{Li}^{+}$ions diffuse in and out of the interlayer region during the redox process. Such a mechanism ensures easy reversibility and long cycle life. However the capacities of these materials are generally limited to 0.5 to $1 \mathrm{e}^{-}$redox change per transition metal ion owing to the limited number of sites available in the interlayer region for the incorporation of lithium ions. Higher capacities may be achieved through materials that are capable of undergoing a wider change in oxidation states, thereby allowing for the accommodation of more than one Li ion per transition metal ion. Such a redox change would require that either the (i) host structure have novel architectures such as tunnel or framework structures with a greater number of potential sites for Li-ion incorporation as well as being stable in both the fully reduced and oxidized states or (ii) that the redox process involves a non-topotactic structural change in which the host electrode material breaks down to facilitate complete reduction of the redox-active metal ion to the elemental metal. The former strategy has been applied in materials such as the NASICON $\mathrm{M}_{2}\left(\mathrm{XO}_{4}\right)_{3}$ framework which are capable of accommodating reversibly up to $5 \mathrm{Li}$ ions per formula unit, and up to 2$3 \mathrm{Li}$ per transition metal ion. ${ }^{3-5}$ Conversion electrodes based on transition metal oxides operate through the latter mechanism through a reaction that can be depicted as:

$$
\mathrm{M}_{x} \mathrm{X}_{y}+n y \mathrm{Li}^{+} \rightarrow y \mathrm{Li}_{n} \mathrm{X}+x \mathrm{M}^{6}
$$

Such a reaction is not limited to oxides but can be extended to sulphides, nitrides, fluorides, pnictides, etc. Despite the high capacities achievable by conversion electrode materials, many of them suffer from a number of drawbacks such as poor reversibility, high coulombic inefficiencies and a large voltage hysteresis. Transition metal sulphides have been explored both as insertion electrodes, for example, $\mathrm{TiS}_{2}$ and $\mathrm{TaS}_{2}{ }^{7}$ as well as as conversion electrodes such as $\mathrm{FeS}_{2}, \mathrm{NiS}_{2}$ and $\mathrm{CoS}_{2} .{ }^{8,9}$ The latter sulfides contain $\left[\mathrm{S}_{2}\right]^{2-}$ disulfide anions and crystallize in the pyrite crystal structure. $\mathrm{FeS}_{2}$, in particular, exhibits excellent reversibility at high temperatures and has, therefore, been explored as a high temperature battery; however, it shows poor reversibility at ambient temperatures . .,9 $^{-1}$

Recently, it has been shown that the compound $\mathrm{VS}_{4},{ }^{10}$ with a unique linear chain structure, exhibits a remarkably high capacity of $\sim 730 \mathrm{mAh} / \mathrm{g}$ at rates as high as $4 \mathrm{C}$ with good capacity retention over $\sim 50$ cycles. ${ }^{11,12}$ Vanadium sulfide was discovered as the mineral patronite in 1906. The crystal structure, determined in $1964,{ }^{13}$ revealed that the material is comprised of $\mathrm{V}^{4+}$ ions coordinated to sulphur dimers forming linear chains extending along the $c$-axis (Figure 1). No attempt was made however to link the crystal structure of the material to its electronic properties, apart from some early suggestions ${ }^{14-16}$, that $\mathrm{VS}_{4}$ appeared to display a Peierls distortion. Recently, it has been suggested from DFT calculations that the material exhibits a band gap of $\sim 1.0 \mathrm{eV} .{ }^{12}$ The open channels in-between the chains offer potential sites for topotactic Li insertion. The detailed mechanism for the redox process however is not well understood. The reasons for the facile reversibility in this system are also not clear. Previous reports ${ }^{11}$ suggest that the reversibility in this system is due to the oxidation 
of the $\mathrm{Li}_{2} \mathrm{~S}$ formed at the end of discharge to form $\mathrm{S}$, so that beyond the first cycle, the electrochemistry is suggested to be akin to that of a Li-S battery. Insights into the mechanism of electrochemical behaviour of conversion materials is challenging owing to the $\mathrm{x}$-ray amorphous nature of the intermediates and products formed during charge/discharge of the battery.

In this contribution, we use density functional theory-based calculations of the electronic structure to establish the Peierls distortion and the nature of the diamagnetic, insulating ground state of the $\mathrm{VS}_{4}$. We then employ a suite of structural characterization tools such as pair distribution function (PDF) analysis, solid state nuclear magnetic resonance spectroscopy (ssNMR) and S K-edge X-ray absorption near-edge spectroscopy (XANES) to examine the electrochemical behaviour in this compound and the mechanisms underpinning the structural transformation. Both ${ }^{6} \mathrm{Li}$ and ${ }^{51} \mathrm{~V}$ NMR spectroscopy are used. ${ }^{51} \mathrm{~V}$ is a spin $7 / 2$ nucleus with a natural abundance of $99.75 \%$ and a relatively small quadrupolar moment, with a chemical shift range that is extremely sensitive to local structure. ${ }^{17}$ The NMR and XANES spectra are compared with model compounds, to help assign specific spectral signatures to different local structures. A rich redox chemistry involving both the anion and the cation is identified, an understanding of which throws valuable insights into the role that metal-ligand covalency plays in controlling the reversibility of such systems.

\section{EXPERIMENTAL AND THEORETICAL METHODS}

Electronic Structure Calculations. Density functional theory-based electronic structure calculations on $\mathrm{VS}_{4}$ were performed using the Vienna Ab-initio Simulation Package (VASP version 5.2) $^{18,19,20,21}$ with the wavefunctions described by a plane-wave basis set and the ionic potentials described by projector augmented wave (PAW) potentials of Blöchl. ${ }^{22,23}$ The energy cut off for the plane waves was set to $500 \mathrm{eV}$ and a grid of at least $100 \mathrm{k}$-points was used for all calculations. The energy convergence criteria was $10^{-5} \mathrm{eV}$. Ground state electronic structures were relaxed with Perdew-Burke-Ernezhof generalized gradient approximated (GGA-PBE) ${ }^{24}$ functionals by optimizing the position of sulfur atoms around the vanadium chains, keeping the V-V bond length fixed. Hyed-Scuseria-Ernezhof (HSE) ${ }^{25}$ screened hybrid functionals were used to calculate the DOS of the dimer and monomer structures, as HSE is known to better estimate band gaps than PBE. Structures were visualized in VESTA. ${ }^{26}$

Materials Preparation. $\mathrm{VS}_{4}$-reduced graphene oxide (rGO) powder was prepared using the synthesis procedure described in a previous paper. ${ }^{12}$ Briefly, GO was prepared from natural graphite powder by the Hummer's Method. ${ }^{27}$ The GO solution $(5 \mathrm{mg} / \mathrm{mL})$ was added to a mixture of sodium orthovanadate and thioacetamide to make a total volume of $120 \mathrm{~mL}$. The solution was transferred to a 150 -mL Teflon-lined stainless steel autoclave and heated up to $160^{\circ} \mathrm{C}$ for $24 \mathrm{~h}$. The product was then filtered, washed with DI water and dried in vacuum at $60^{\circ} \mathrm{C}$ for $6 \mathrm{~h} . \mathrm{K}_{3} \mathrm{VS}_{4}$ and $\mathrm{LiVS}_{2}$, which were used as model compounds for the XANES measurements, were prepared by a sealed tube method. $\mathrm{K}_{3} \mathrm{VS}_{4}$ was synthesized by carefully 
mixing together stoichiometric amounts of $\mathrm{K}_{2} \mathrm{~S}, \mathrm{~V}$, and $\mathrm{S}$ and heating the resulting mixture in a sealed tube at $650^{\circ} \mathrm{C}$ for 20 hours. $\mathrm{LiVS}_{2}$ was prepared by grinding together stoichiometric quantities of $\mathrm{Li}_{2} \mathrm{~S}, \mathrm{~V}$ and $\mathrm{S}$ and heating the resulting mixture at $750^{\circ} \mathrm{C}$ for 20 hours. The other model compounds, $\mathrm{Li}_{2} \mathrm{~S}$ and $\mathrm{S}$, were sourced from Sigma-Aldrich.

Electrochemical Characterization. The electrodes were made of $\mathrm{VS}_{4}-\mathrm{rGO}$ composite (rGO 3\% by weight) Ketjen Black and polyvinylidine fluoride (PVDF) binder in a weight ratio of 80:10:10 cast onto copper foil. Coin-type half cells containing the $\mathrm{VS}_{4}-\mathrm{rGO}$ films, Li metal as counter electrode, borosilicate glass fibre separator (Whatman) and electrolyte $\left[\left(1 \mathrm{M} \quad \mathrm{LiPF}_{6}\right.\right.$ in ethylene carbonate (EC) /dimethyl carbonate (DMC) 1:1 $((\mathrm{v} / \mathrm{v})$ Merck)] were assembled in an argon filled glove box. The batteries were cycled between $0-3.0 \mathrm{~V}$ at rates of $\mathrm{C} / 5$ or $\mathrm{C} / 10$ in galvanostatic mode in an Arbin battery cycler. For ex-situ characterization, after cycling to a specific cutoff potential, the films were extracted from the coin cells, rinsed with dimethyl carbonate solvent and dried in a vacuum. The electrode material was scraped off the film for solid state NMR, ex-situ PDF and XANES measurements.

X-ray Diffraction (XRD). Laboratory powder diffraction was carried out using an Empyrean powder diffractometer equipped with a $\mathrm{Cu}$ source $(\mathrm{Cu} \mathrm{K \alpha}=1.5418 \AA)$. In-situ XRD was collected at beamline 11-BM $(\lambda=0.4137 \AA)$ of the Advanced Photon Source (APS) at Argonne National Laboratory. For in-situ XRD measurements, electrode pellets were prepared by mixing the $\mathrm{VS}_{4}$-rGO nanocomposite with "Super P" carbon, (Alfa Aesar), carbon black, and polytetrafluoroethylene (PTFE) binder (Sigma-Aldrich) in the mass ratio 6:1:1:2. The pellets were assembled into the AMPIX electrochemical cell ${ }^{28}$ with a glass fibre separator (Whatman GF/A), Li metal foil and liquid electrolyte $(1 \mathrm{M} \mathrm{LiPF} 6$ in $3: 7 \mathrm{v}: \mathrm{v}$ (EC:DMC) from Tomiyama Pure Chemical Industries) within an argon glovebox. The electrolyte and binder used in the in-situ XRD experiments were different from those used for the ex-situ measurements, as the in-situ experiment required the cathode to be in the form of a pellet so that it could be cycled inside the AMPIX. A series of experiments were performed to identify the optimum ratio of electrode components $(6: 1: 1: 2)$, to ensure good cyclability and conductivity within the AMPIX cell. In particular, both Super P and carbon black were required to obtain electrochemistry that resembled that obtained for electrodes cast on $\mathrm{Cu}$ foil (used for the ex-situ studies). The cells were cycled galvanostatically against lithium at constant current at a rate of $\mathrm{C} / 10$, between $0.0-3.0 \mathrm{~V}$. Data were collected during the first two discharge/charge cycles.

Pair Distribution Function Analysis. For ex-situ PDF measurements, the electrode materials were scraped off the copper film after cycling and then loaded into kapton capillaries.

X-ray total scattering data were collected at Beamline 11-ID-B of the APS, Argonne National Laboratory. High-energy X-rays $(\sim 58 \mathrm{keV}, \lambda=0.2128 \AA)$ were used in combination with a large amorphous-silicon based area detector (Perkin-Elmer) to collect total scattering data to high values of momentum transfer $\left(\mathrm{Q}_{\max }=\sim 22 \AA\right)$. The scattering images were reduced to one-dimensional data using Fit2d. ${ }^{29}$ The data were corrected for Compton 
scattering effects, self absorption, background scattering and detector effects within PDFgetX2 $2^{30}$ and Fourier transformed to get G(r), the PDF. Structure refinement of the PDF data was carried out using the PDFgui software. ${ }^{31}$

X-ray Absorption Spectroscopy. The XANES measurements were carried out in beamline 9-BM-B/C at the APS, Argonne National Laboratory. In order to minimize absorption effects, both the samples recovered from different states of charge/discharge and the standards were combined with carbon so that the weight percent of the $\mathrm{VS}_{4}-\mathrm{rGO} / \mathrm{V}$ standard in the mixture was $<5 \%$. They were then mounted onto a sample holder with a polycarbonate film $(<4 \mu \mathrm{m}$ thick) and measurements at the $\mathrm{S}$ K-edge were recorded in fluorescence yield mode. Energy calibration was done with reference to the lowest energy $S$ K-edge absorption peak of a sodium thiosulfate standard, ${ }^{32}$ which was assumed to be at $2469.2 \mathrm{eV}$. The data was analysed using the Athena software package. ${ }^{33}$

NMR Analysis. ${ }^{6} \mathrm{Li}$ Magic Angle Spinning (MAS) NMR experiments were performed on $\mathrm{VS}_{4}$-rGO samples that were cycled with coin cells containing ${ }^{6} \mathrm{Li}$ enriched lithium metal. The spectra were acquired on a Bruker Avance-300 spectrometer at a ${ }^{6} \mathrm{Li}$ Larmor frequency of 44.1 MHz. All the experiments were carried out with a Bruker $2.5 \mathrm{~mm}$ MAS probe spinning at frequencies of $20 \mathrm{kHz}$ with a rotor synchronised Hahn echo pulse sequence. A $90^{\circ}$ pulse of $2.75 \mu \mathrm{s}$ with a relaxation delay of $10 \mathrm{~s}$ was used. ${ }^{51} \mathrm{~V}$ MAS NMR experiments were carried out on a Bruker Avance $400 \mathrm{MHz}(9.4 \mathrm{~T})$ spectrometer at a ${ }^{51} \mathrm{~V}$ Larmor frequency of $105.2 \mathrm{MHz}$ with a Bruker $2.5 \mathrm{~mm}$ MAS probe spinning at frequencies of $25 \mathrm{kHz}$. An echo sequence with a $\pi / 2$ pulse of $1.5 \mu$ s and a recycle delay of $5 \mathrm{~s}$ was used. The spectra were referenced to solid $\mathrm{NH}_{4} \mathrm{VO}_{3}$ at $-565.5 \mathrm{ppm}$.

\section{RESULTS}

\section{Crystal structure and DFT studies of $\mathrm{VS}_{4}$}

Figure 1 displays the experimental crystal structure of $\mathrm{VS}_{4}$, showing linear chains formed along the monoclinic $c$ axis of vanadium atoms in approximately 8 -fold coordination of $\mathrm{S}$, with all of the $\mathrm{S}$ present in dimerized persulfide $\mathrm{S}_{2}{ }^{2-}$ units. In the experimental structure [Figure 1(a)], the $\mathrm{V}-\mathrm{V}$ distances along the c direction display an alternation with shorter $(2.8 \AA)$ and longer $(3.2 \AA)$ distances. By shifting the $z$ coordinate of the $\mathrm{V}$ atom to the closest special position, we recover the undistorted structure of $\mathrm{VS}_{4}$ with equal $\mathrm{V}-\mathrm{V}$ distances [Figure 1(b)]. DFT calculations suggest that the lower energy, relaxed structure is diamagnetic with a PBE-GGA band gap close to $1 \mathrm{eV}$, in agreement with the prior work of Rout, C. S. et $\mathrm{al}^{12}$. This is seen in Figure 2(a). The undimerized structure, within DFT, appears to have lost its band gap and displays metallic densities of state, at least in the absence of spin-polarization, and in the absence of any considerations of electron correlation, as seen in Figure 2(b). In order to understand the possible energetics of the true, Peierls distorted state, we have monitored the changes in the energetics upon stepping through the distortion, starting with the undistorted structure. Figure 2(c) displays the DFT energetics, referenced to the ground state of the distorted structure, per 40 atom $\mathrm{VS}_{4}$ unit cell, as a function of the $\mathrm{V}-\mathrm{V}$ bond length alternation. The two traces in this panel correpond to static 
displacements of the $\mathrm{V}$ along the $\mathrm{c}$ axis, and displacements accompanied by full structural relaxation (labelled "relaxed"). It is seen that the minimum energy indeed corresponds to a $0.4 \AA$ bond alternation. The depth of the well, close to $0.5 \mathrm{eV}$ per unit cell, would, however, suggest that the undistorted state may be thermally accessible at elevated temperatures.

\section{Electrochemical Characterization}

The electrochemical performance of the $\mathrm{VS}_{4}-\mathrm{rGO}$ composite was studied by galvanostatic cycling at a rate of $\mathrm{C} / 10$ between 3.0 and $0.01 \mathrm{~V}$ (Figure 3). The first discharge curve exhibits a flat plateau at $1.9 \mathrm{~V}$ (marked ' $\mathrm{A}$ '), characteristic of a two-phase reaction. After incorporation of $2.4 \mathrm{Li}$ per formula unit, corresponding to a capacity of $\sim 360 \mathrm{mAh} / \mathrm{g}$, the profile slopes gradually down to $0.01 \mathrm{~V}$. Smaller less distinct processes are observed at $\sim 1.6$ $\mathrm{V}$ ('B') and $0.7 \mathrm{~V}$ ('C'). Although the total discharge capacity in the first cycle is $\sim 2430$ $\mathrm{mAh} / \mathrm{g}$, the capacity at and below $0.7 \mathrm{~V}$ is largely attributed to formation of a solid electrolyte interphase (SEI) arising due to electrolyte decomposition. The capacity down to $0.7 \mathrm{~V}$ is $\sim 1200 \mathrm{mAh} / \mathrm{g}$, which agrees with the theoretical capacity corresponding to reaction of $\mathrm{VS}_{4}$ with $8.0 \mathrm{Li}$ per formula unit to form $\mathrm{V}$ metal and $\mathrm{Li}_{2} \mathrm{~S}$. Upon charging, the delithiation process is characterized by a rapid rise in potental to $1 \mathrm{~V}$ and then a more gradual sloping voltage increase to $2.3 \mathrm{~V}$. A noticeable, flatter process is seen at $\sim 2.3 \mathrm{~V}$ (' $\mathrm{D}$ '), which is similar in length (i.e., capacity) to that seen at $\sim 1.9 \mathrm{~V}$ on discharge. The charge capacity is $\sim 1200 \mathrm{mAh} / \mathrm{g}$ in the first cycle. The second cycle shows a more sloping profile compared to the first cycle, with a discharge capacity of $\sim 1200 \mathrm{mAh} / \mathrm{g}$ that is recovered upon charging. Of note, the $1.9 \mathrm{~V}$ process is less distinct on the second discharge, but the process at $\sim 2.3 \mathrm{~V}$ is similar to that seen in the $1^{\text {st }}$ cycle.

\section{In-situ X-ray Diffraction}

The structural evolution of the pristine material upon galvanostatic cycling was investigated by in-situ X-ray diffraction (SI Figure 1). The capacity obtained from the in-situ cell was $\sim 800 \mathrm{mAh} / \mathrm{g}$ in the first discharge. The lower capacity obtained may be related to poor $\mathrm{Li}$ ion diffusion through the pellet used as the positive electrode (as opposed to copper film substrate, which was used for the ex-situ coin cells). Only the first two most intense (110 and 020) reflections of the pristine material are clearly visible, and even these are broadened relative to the diffraction pattern obtained ex-situ, due to the high background from the cell components (electrolyte, Li metal, glass fibre separator etc). A continuous decrease, rather than a shift, in the integrated intensity of the 110 and 020 reflections with discharge indicates that $\mathrm{VS}_{4}$ starts to transform to a more disordered and/or amorphous phase, right from the beginning of discharge. The $\mathrm{VS}_{4}$ reflections disappear at the end of discharge and do not reappear upon charging. Prior X-ray diffraction of samples prepared ex-situ ${ }^{11}$ observed the formation of $\mathrm{V}$ metal and $\mathrm{Li}_{2} \mathrm{~S}$ at the end of discharge; no reflections from any crystalline products at the end of discharge or upon charging the material were seen in this XRD study, possibly because of poorer signal-to-noise and/or smaller particle sizes. We have, therefore, used a range of short range characterization techniques, namely ${ }^{6} \mathrm{Li}$ and ${ }^{51} \mathrm{~V} \mathrm{NMR}, \mathrm{S} \mathrm{K}$-edge XANES and Pair Distribution Function analysis to probe the nature of the amorphous or nanoparticulate products formed during the charge/discharge process. 


\section{NMR. 1st Discharge}

${ }^{6} \mathrm{Li} \mathrm{NMR}$ was carried out on samples stopped at various states of discharge (Figure 4). A resonance at $-0.2 \mathrm{ppm}$ is seen upon lithiation to an amount corresponding to $0.66 \mathrm{Li}$ per $\mathrm{VS}_{4}$ formula unit (denoted as "Li 0.66"), corresponding to a specific capacity of $100 \mathrm{mAh} / \mathrm{g}$. Since the ${ }^{6} \mathrm{Li} /{ }^{7} \mathrm{Li}$ NMR chemical shifts of diamagnetic materials generally lie in the range of $0 \pm 3 \mathrm{ppm}$, the resonance at $\mathrm{Li} 0.66$ is therefore attributed to a diamagnetic intermediate, tentatively assigned at this point to $\mathrm{V}$ in a higher oxidation state $(+5)$. As lithiation progresses, this resonance shifts to slightly higher frequency $(\sim 0.5 \mathrm{ppm})$. Upon further lithiation, at $\mathrm{Li} 2.0$ (i.e., at the end of process A), a broad resonance close to $\sim 25 \mathrm{ppm}$ is observed. In general, such a broad and shifted resonance is due to hyperfine interactions arising due to lithium ions being close to paramagnetic ions, ${ }^{34}$ and is therefore indicative of formation of reduced $\mathrm{V}^{4+}$ species at this stage of the discharge process. This broad feature

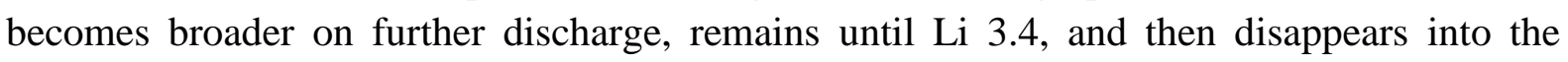
baseline. The growth of a peak at $2.2 \mathrm{ppm}$ due to $\mathrm{Li}_{2} \mathrm{~S}$ formation also starts to become evident at this stage ( $\mathrm{Li}$ 2.0) with this resonance becoming more prominent and growing in intensity upon further lithiation (between $\mathrm{Li} 2.67-\mathrm{Li} \mathrm{8.0)}$. The resonance seen at $\sim 0 \mathrm{ppm}$ towards the end of discharge is attributed to be due to diamagnetic components such as $\mathrm{LiOH}, \mathrm{Li}_{2} \mathrm{CO}_{3}$ and other lithium salts arising from SEI formation at low voltages ${ }^{35}$ on both $\mathrm{VS}_{4}$ and the various carbons (including graphene oxide) used to fabricate the electrode. The integrated intensity of this peak increases in intensity with discharge until Li 2.0 (see plot in supplemental figure, SI.2) then decreases in intensity from $\mathrm{Li} 2.0$ to $\mathrm{Li} 2.67$. This is followed by a continuous growth in the intensity of this peak from $\mathrm{Li} 2.67$ to $\mathrm{Li}$ 8.0. Therefore, in the initial stages of the discharge profile, this peak is attributed to the diamagnetic $\mathrm{V}^{5+}$-containing intermediate, but beyond $\mathrm{Li} 2.66$, the increase in intensity is ascribed at least in part to the growth of a second overlapping peak from the diamagnetic species that form part of the SEI as discharge progresses down to $0 \mathrm{~V}$ (SI. 2).

The local structure of vanadium compounds can also be probed by using ${ }^{51} \mathrm{~V}$ NMR spectroscopy. The starting material, $\mathrm{VS}_{4}$, which has $\mathrm{V}$ in +4 oxidation state, might be expected to be paramagnetic, and thus would not be expected to give readily detectable high resolution NMR spectrum owing to the extreme line broadening resulting from fast relaxation of the metal nuclei and the large hyperfine shifts. The observation of a ${ }^{51} \mathrm{~V}$ NMR spectrum for the pristine material (Figure 5), with an isotropic shift of $\sim 161 \mathrm{ppm}$, suggests, however, that it is actually diamagnetic. Spin-pairing in this material must arise due to the Peierls distortion described previously and observed in the DFT calculations, which leads to the observed alternation in $\mathrm{V}-\mathrm{V}$ distances $(3.2 \AA \text { and } 2.8 \AA)^{13}$ as well as the nearly $1 \mathrm{eV}$ semiconducting gap in the density of states. Simulations of the ${ }^{51} \mathrm{~V}$ spectrum (see SI. 3) yielded a large chemical shift anisotropy $(\delta(\mathrm{CSA})=-1520 \mathrm{ppm}$, asymmetry parameter, $\eta(\mathrm{CSA})=0.6)$ and a moderate quadrupolar coupling constant, $\mathrm{C}_{\mathrm{Q}}$ of $134 \mathrm{kHz},(\eta(\mathrm{Quad})=$ 0.4). While the $\mathrm{C}_{\mathrm{Q}}$ determination (and the values of the CSA and $\mathrm{C}_{\mathrm{Q}}$ asymmetry parameters) is less reliable due to the difficulty in exciting the whole spectrum, the large CSA is noteworthy, its large value being ascribed to the anisotropy in $\mathrm{V}$ bonding (due to the formation of $\mathrm{V}-\mathrm{V}$ bonds). 
The ${ }^{51} \mathrm{~V}$ NMR of discharged samples was carried out at two different field strengths, 9.4 and 16.4 T. The ${ }^{51} \mathrm{~V}$ NMR of samples measured at $9.4 \mathrm{~T}$ are given in Figure 5. Upon lithiation to $\mathrm{Li}$ 0.66, in addition to the broad resonance characteristic of the pristine sample, an additional site characterized by an isotropic shift at $\sim 1430 \mathrm{ppm}$ is observed. This chemical shift is found to be close to that of a model compound, $\mathrm{K}_{3} \mathrm{VS}_{4}(1375 \mathrm{ppm})$, which is comprised of diamagnetic $\mathrm{V}(\mathrm{V})$ ions bound to $\mathrm{S}^{2-}$ sulphur ligands to form isolated tetrahedral units (SI.4). The analogous material, $\mathrm{Li}_{3} \mathrm{VS}_{4}$, has not been synthesized, however, the dimethyl formamide adduct phase $\mathrm{Li}_{3} \mathrm{VS}_{4}$. $2 \mathrm{DMF}$ has been prepared. ${ }^{36}$ The solution ${ }^{51} \mathrm{~V}$ NMR of this compound in $\mathrm{Me}_{2} \mathrm{SO}$ exhibits a ${ }^{51} \mathrm{~V}$ NMR shift of $1388 \mathrm{ppm} .{ }^{37}$ The NMR shifts of the tetrathiovanadate ion $\left(\mathrm{VS}_{4}{ }^{3-}\right)$ in a range of other solvents are in the range of 1395-1400 ppm. ${ }^{35-37}$ All this data suggests that the resonance at $\sim 1430 \mathrm{ppm}$ is due to a material with composition close to $\mathrm{Li}_{3} \mathrm{VS}_{4}$, a material in which the $\mathrm{S}_{2}{ }^{2-}$ sulfur ions have been reduced to $\mathrm{S}^{2-}$, while the vanadium ions have been oxidized to $\mathrm{V}^{5+}$, in agreement with the ${ }^{6} \mathrm{Li}$ NMR spectrum of this material. Upon further lithiation to a specific capacity of $300 \mathrm{mAh} / \mathrm{g}$ (Li 2.0; end of process A), the peak at $1430 \mathrm{ppm}$ diminishes and a new environment characterized by an isotropic shift at $\sim-546 \mathrm{ppm}$ is observed (Figure 5, SI. 5). In general, the vanadium nucleus is more deshielded as the polarizability of the ligand increases and vanadium compounds with sulphur ligands generally have higher frequency shifts compared to those with oxide ligands. ${ }^{37} \mathrm{~V}$ shifts of $\sim-550 \mathrm{ppm}$ are not therefore characteristic of $\mathrm{V}(\mathrm{V})$ sulphides and are more commonly exhibited by the vanadium oxides (vanadates). ${ }^{40,}{ }^{41}$ However, it has been observed that reduction of $\mathrm{V}(\mathrm{V})$ to form mixed valent $\mathrm{V}(\mathrm{IV}) / \mathrm{V}(\mathrm{V})$ vanadium oxides can result in large negative shifts from $\sim-550 \mathrm{ppm}$ to $\sim-1440 \mathrm{ppm} .{ }^{41}$ Thus, the negative shift from $\sim 1440 \mathrm{ppm}$ to $-547 \mathrm{ppm}$ is similarly ascribed to partial reduction of $\mathrm{V}(\mathrm{V})$ to $\mathrm{V}(\mathrm{IV})$ as the discharge progresses. The huge shift in the ${ }^{51} \mathrm{~V}$ NMR from $\sim 1440 \mathrm{ppm}$ to $\sim-550 \mathrm{ppm}$ is attributed to the hyperfine interaction of $\mathrm{V}^{5+}$ ions with nearby $\mathrm{V}^{4+}$ ions (in the $1^{\text {st }} \mathrm{V}^{5+}$ cation coordination shell) in the mixed valent compound formed at this stage. Note that the $\mathrm{V}^{4+}$ ions are not likely to be observed under the conditions used to acquire these spectra. The ${ }^{6} \mathrm{Li}$ NMR spectrum for $\mathrm{Li}=2.0$ exhibits a broad feature at $\sim 25 \mathrm{ppm}$ further supporting the formation of a paramagnetic material comprised of both $\mathrm{V}(\mathrm{IV})$ and $\mathrm{V}(\mathrm{V})$. Beyond this, at $\mathrm{Li}$ 2.68, a resonance at $5657 \mathrm{ppm}$ is observed. The ${ }^{51} \mathrm{~V}$ NMR spectrum of the body centered cubic (bcc) form of elemental $\mathrm{V}$ (the thermodynamic phase ${ }^{42}$ ) exhibits a shift of $\sim 5230 \mathrm{ppm}$ (SI. 6). The shift at $5657 \mathrm{ppm}$ is also attributed to $\mathrm{V}$ metal, the discrepancy being attributed to the formation of the face centered cubic (fcc) polymorph $\mathrm{V}$ upon discharge. This is supported by the PDF data shown in the following section. The spectra obtained at a field strength of $16.4 \mathrm{~T}$ concur with the above results (SI. 7). However, resonances due to V metal are observed (SI. 8) in this set of samples right from the beginning of discharge possibly due to instability of some of the products, disproportionation leading to metal deposition.

\section{NMR. $1^{\text {st }}$ Charge.}

The ${ }^{6} \mathrm{Li} \mathrm{NMR}$ resonances at $2.2 \mathrm{ppm}$ and $\sim 0.5 \mathrm{ppm}$, from $\mathrm{Li}_{2} \mathrm{~S}$ and SEI components, respectively, remain on charging to $0.5 \mathrm{~V}$ (Figure 6). The Li resonance from the SEI is a superposition of several $\mathrm{Li}$ environments resonating between $-1 \mathrm{ppm}(\mathrm{LiF})$ and $+1 \mathrm{ppm}$ $(\mathrm{LiOH})$. Thus, the small variations in shift in the resonance from $0 \mathrm{ppm}$ (at the end of 
discharge) to $\sim 0.5 \mathrm{ppm}$ on charging to $0.5 \mathrm{~V}$ and then $\sim 0 \mathrm{ppm}$, as charging progresses further, are ascribed to slight variations in the SEI composition between the different samples. At 2.3 $\mathrm{V}$, ie., at the end process $\mathrm{D}$, a broad resonance at $\sim 8 \mathrm{ppm}$ is observed along with a slight decrease in the $\mathrm{Li}_{2} \mathrm{~S}$ resonance. This is attributed to the partial reformation of the $\mathrm{Li}_{3+\mathrm{x}}, \mathrm{VS}_{4}$ intermediate, the different shift from that observed on discharge indicating a slightly different Li content and vanadium oxidation state. The peak at $\sim 2.2 \mathrm{ppm}$ decreases in intensity as charging progresses and disappears at $3 \mathrm{~V}$ indicating that $\mathrm{Li}_{2} \mathrm{~S}$ further converts to another phase as charging progresses.

On charging to $2.3 \mathrm{~V}$, i.e., at the end of process $\mathrm{D}$, a ${ }^{51} \mathrm{~V}$ NMR resonance is seen at $-568 \mathrm{ppm}$ (Figure 7). The lineshape of this resonance differs noticeably from that of the pristine material in that it has a sharp central transition, with a broad spinning sideband manifold from the satellite transitions. The chemical shift anistropy is noticeably smaller for the $-568 \mathrm{ppm}$ resonance indicating that it arises from a more symmetric local environment. The extraction of NMR parameters, which would give further insights into the causes of the broadening of these spectra requires excitation of the entire spinning sideband manifold at two different field strengths, which was not possible under the present experimental conditions. The shift (and sideband manifold) of this resonance is close to that of the $\mathrm{Li}_{3+\mathrm{x}} \mathrm{VS}_{4}$ resonance observed during the discharge process (see Figure SI. 5) suggesting that a structurally related intermediate is formed during charging, however, with a slightly different Li content and vanadium oxidation state. This proposal is consistent with the ${ }^{6} \mathrm{Li}$ NMR spectra. The intensity of this resonance increases on charging up to $3 \mathrm{~V}$. A broad intense hump is observed under the main (sharp) resonance, which is more prominent in the $3 \mathrm{~V}$ sample. This is ascribed to amorphous $\mathrm{VS}_{4}$, the broadening arising either from electron-nuclear dipolar coupling due to paramagnetic $\mathrm{V}^{4+}$ ions caused by non-stoichiometry, or regions of the sample that do not undergo a Peierls distortion, and/or simply a distribution of local environments in the disordered material.

\section{S K-edge XANES Spectroscopy.}

S K-edge XANES was carried out in order to investigate the evolution of the oxidation states of $\mathrm{S}$ as a function of state of charge/discharge. Figure 8 and Figure SI. 9 show the normalized absorption spectra and first derivative of the normalized absorption spectra, respectively, of the lithiated $\mathrm{VS}_{4}$ phases and a series of S-containing model compounds. S K-edge XANES of transition metal sulphides are particularly useful as the relative shifts and intensities of the pre-edge peak are sensitive to the covalency of the metal-ligand bond, yielding information on not just the oxidation state of the $\mathrm{S}$ but also of the transition metal ion. The pre-edge features in the $\mathrm{S}$ K-edge spectra arise from excitation of electrons from the $\mathrm{S} 1 s$ orbitals to $\mathrm{S} 3 p / \mathrm{V} 3 d$ antibonding states. ${ }^{43,}{ }^{44}$ The higher the positive charge on the metal, the more stabilized the hybridized S 3p orbitals are. As a result, the pre-edge peaks shift to lower energies with increasing effective positive charge on the metal. The S K-edge spectra of the model compounds demonstrate this trend with $\mathrm{K}_{3} \mathrm{VS}_{4}\left(\mathrm{~V}(\mathrm{~V})\right.$ ) and $\mathrm{LiVS}_{2}(\mathrm{~V}(\mathrm{IV})$ ) (both containing $\mathrm{S}^{2-}$ ) exhibiting pre-edge peaks at $2466.8 \mathrm{eV}$ and $2467.2 \mathrm{eV}$, respectively. Changes

in $\mathrm{S}$ oxidation state and ionicity produce more noticeable changes: $\mathrm{VS}_{4}$ with $\mathrm{S}_{2}{ }^{2-}$ (-1 formal oxidation state) dimers will have a lower energy $1 \mathrm{~s}$ orbital as compared to $\mathrm{S}^{2-}$ leading to a 
higher energy pre-edge peak at $2469.0 \mathrm{eV}$. S exhibits a peak at still higher energies at 2469.8 $\mathrm{eV}$. $\mathrm{Li}_{2} \mathrm{~S}$ in which there is no significant covalent interaction with metal centers has no preedge features and exhibits characteristic absorption peaks at $2475.7 \mathrm{eV}$ and $2478.4 \mathrm{eV}$. The experimentallly observed absorption profile of $\mathrm{Li}_{2} \mathrm{~S}$ (Figure 8) also contains features at $2469.8 \mathrm{eV}$ similar to that in $\mathrm{S}$ which may be attributed to some decomposition of $\mathrm{Li}_{2} \mathrm{~S}$ to $\mathrm{S}$, possibly due to slight air exposure before taking the measurements.

The shifts of the model compounds can be used as a fingerprint to assign the oxidation state of $\mathrm{S}$ in the cycled samples. The XANES spectrum of the sample discharged to Li 0.66 exhibits peaks at $2469.0 \mathrm{eV}$ and $2466.9 \mathrm{eV}$ corresponding to $\mathrm{VS}_{4}$ and an intermediate with a structure similar to that of $\mathrm{K}_{3} \mathrm{VS}_{4}$ (possibly $\mathrm{Li}_{3} \mathrm{VS}_{4}$ ), respectively. At Li 2.68, the peak at $2469.0 \mathrm{eV}$ has disappeared and only the peak at $2466.9 \mathrm{eV}$ remains. At the end of discharge, characteristic features in the absorption spectra due to $\mathrm{Li}_{2} \mathrm{~S}$ are observed. On charging, the absorption profile at $2.3 \mathrm{~V}$ is similar to that of $\mathrm{K}_{3} \mathrm{VS}_{4}$ suggesting that the charging process occurs through reformation of the same $\mathrm{Li}_{3} \mathrm{VS}_{4}$-like intermediate. At the end of charge, the absorption profile exhibits a peak at $2469.0 \mathrm{eV}$ characteristic of $\mathrm{VS}_{4}$ suggesting partial reformation to a phase that is similar to $\mathrm{VS}_{4}$ upon charging and that, significantly, contains $\mathrm{S}_{2}{ }^{2-}$ ions.

\section{Pair Distribution Function Analysis.}

PDFs obtained from X-ray total scattering data have proven to be an invaluable tool to investigate the structures of $\mathrm{x}$-ray amorphous/nanoparticulate intermediates formed during the cycling of Li-ion batteries. ${ }^{45,46,47,48}$ Figure 9 shows the ex-situ PDF patterns obtained in the first discharge cycle. The PDF pattern at $\mathrm{Li}=0.0$ corresponds to that of $\mathrm{VS}_{4}$. Correlations due to S-S dimers of $\mathrm{VS}_{4}$ are seen at $2.0 \AA$ (marked 'I') while the correlations at $3.2 \AA$ correspond to the $\mathrm{V}-\mathrm{V}$ distance in $\mathrm{VS}_{4}$ ('III'). Within the unit cell, the ratio of $\mathrm{V}-\mathrm{V}$ distances at 3.2 and $2.8 \AA$ is $2: 1$, and thus the latter distance therefore appears only as a very small peak in even the simulated PDF and is hardly visible in the experimental PDF of the pristine material. However the presence of the correlation at $3.2 \AA$ is evidence of the distortion in the $\mathrm{V}-\mathrm{V}$ distances in the material. The correlation at $2.4 \AA$ ('II') corresponds to the V-S distance in $\mathrm{VS}_{4}$ but this overlaps with correlations due to bond distances in fcc $\mathrm{V}$ metal $(2.6 \AA)$ and $\mathrm{Li}_{2} \mathrm{~S}(2.5 \AA)$. Up to $\mathrm{Li} 2.0$ (till the end of process 'A'), the correlations beyond $4.0 \AA$ are quite broad, suggesting a range of bond distances characteristic of a highly amorphous intermediate formed at this stage. From Li 2.68 (from process 'B') down to 0V, sharper more well defined correlations due to fcc V are seen. A PDF refinement of the product formed at the end of discharge confirms that the phase formed at the end of discharge is the metastable phase fcc $\mathrm{V}$ (particle size of $\sim 6.5 \mathrm{~nm}$, SI. 10). These correlations weaken upon charging and reappear again upon discharge in the second cycle. The changes seen in the PDF patterns are clearer in the difference PDF patterns in which each PDF pattern is subtracted from the one prior to it in the discharge curve (Figure 10). A negative correlation in the difference PDF is suggestive of the particular bond being broken or a correlation disappearing while a positive correlation indicates that a bond (correlation) is being formed. As discharge progresses, the negative correlation marked ' $A$ ' in the inset corresponds to the 
breaking of the S-S dimers at $2.0 \AA$. This is accompanied by a positive correlation at $2.2 \AA$ (marked ' $\mathrm{B}$ '). This is attributed to the V-S bond in the tetrahedral $\mathrm{VS}_{4}$ units of the $\mathrm{Li}_{3} \mathrm{VS}_{4}$ species formed at this stage. This bond then breaks leading to formation of $\mathrm{V}$ metal as shown in the inset. Although correlations due to $\mathrm{VS}_{4}$ at the end of charge are not sharp, negative correlations due to fcc $\mathrm{V}$ upon charging indicate unambiguously that the $\mathrm{V}$ metal is consumed as charging progresses. This demonstrates that reversibility in this system is not solely due to $\mathrm{Li}_{2} \mathrm{~S}$ reacting to form $\mathrm{S}$ as has been suggested previously, ${ }^{11}$ but involves reaction of $\mathrm{V}$ metal and at least partial conversion back to a phase structurally related to $\mathrm{VS}_{4}$. A Principal Component Analysis (PCA) performed on the entire dataset of the PDF data ${ }^{49}$ provided further confirmation of the multiple phases formed during the charge-discharge process. It was found that three eigenvectors were required to explain $98 \%$ of the variance in the experimental data while a fourth eigenvector adds only a marginal improvement and is attributed to noise, and therefore the analysis yields three principal components (SI. 11). The first two components are dominated by contributions from fcc $\mathrm{V}$ and $\mathrm{VS}_{4}$, respectively, and the third component is attributed to formation of intermediate phases. The PCA is not sensitive to the small changes in lithium content in $\mathrm{Li}_{3+\mathrm{x}} \mathrm{VS}_{4}$ identified by $\mathrm{NMR}$ spectroscopy. The analysis indicate the growth of the intermediate phase upto Li 2.0 followed by formation of fcc $\mathrm{V}$ metal which grows till the end of discharge consistent with the NMR and PDF data (SI. 12).

\section{DISCUSSION}

$\mathrm{VS}_{4}$ has a structure comprised of $\mathrm{V}^{4+}$ ions coordinated to four sets of sulphur dimers to form linear chains along the c-axis. The results presented here (in particular the ${ }^{51} \mathrm{~V}$ NMR spectrum) provide clear evidence for the electronic structure of this material (which has prior to this not been clearly described), namely that it contains paired electrons (in V-V bonds) as opposed to the unpaired electrons typically observed in $\mathrm{V}^{4+}$ ions. This is consistent with DFT calculations of the densities of states of $\mathrm{VS}_{4}$ as well as studies of the energy stabilization obtained by going from an undistorted, paramagnetic and metallic state to the actual distorted/dimerized state The metal-metal distances seen in $\mathrm{VS}_{4}$ are consistent with those seen in other Peierls distorted compounds such as $\beta-\mathrm{VO}_{2}{ }^{50}$ The large ${ }^{51} \mathrm{~V} \mathrm{CSA}$ is ascribed to the anisotropy in $\mathrm{V}$ bonding (due to the formation of $\mathrm{V}-\mathrm{V}$ bonds) as is observed in $\beta-\mathrm{VO}_{2}$, which exhibits a shift anisotropy of $\sim 1159 \mathrm{ppm}$. Peierls distortions are frequently observed in a range of other 1-dimensional and 2-dimensional transition metal compounds, such as $\mathrm{NbSe}_{3}$ and $\mathrm{TaS}_{3}$, materials in which the transition metal ion has partially filled d-levels, and where a dimerization serves to lift the degeneracy at the Fermi level and lower the electronic energy of the system as a whole. ${ }^{51}$ Metal-insulator transitions are characteristic of Peierls distorted compounds and further studies are underway to study this phenomenon in this material.

$\mathrm{VS}_{4}$ undergoes a complex series of redox reactions on lithiation. Initially the sulphur dimers in $\mathrm{VS}_{4}$ are broken and the $\mathrm{VS}_{4}$ is converted to a phase with a stochiometry close to $\mathrm{Li}_{3} \mathrm{VS}_{4}$ (analogous to $\mathrm{K}_{3} \mathrm{VS}_{4}$ ) in the plateau region (A). This process involves an unusual internal redox reaction whereby one electron from $\mathrm{V}^{4+}$ is transferred to $\mathrm{S}_{2}{ }^{2-}$ dimers (along with $3 \mathrm{e}^{-}$from the external circuit), the $\mathrm{V}^{4+}$ being oxidized to $\mathrm{V}^{5+}$ and $\mathrm{S}_{2}{ }^{2-}$ being completely 
reduced to $\mathrm{S}^{2-}$ resulting in the formation of $\mathrm{Li}_{3} \mathrm{VS}_{4}$. Consistent with this, the phase that is formed is diamagnetic, giving rise to a characteristic diamagnetic signal in the ${ }^{6} \mathrm{Li} \mathrm{NMR}$ spectrum (at $\sim 0 \mathrm{ppm}$ ) and a ${ }^{51} \mathrm{~V}$ resonance at $\sim 1430 \mathrm{ppm}$. The intensity of the ${ }^{51} \mathrm{~V}$ resonance is, however, quite low and it is likely a result of a relatively long spin-lattice $\left(\mathrm{T}_{1}\right)$ relaxation process for ${ }^{51} \mathrm{~V}$ in the tetrahedral environment, the signal not being fully recovered in the $5 \mathrm{~s}$ relaxation delay used in the NMR experiments. This proposal is supported by our measurements of the analogous compound $\mathrm{K}_{3} \mathrm{VS}_{4}$, which had a $\mathrm{T}_{1}$ time of greater than $25 \mathrm{~s}$.

In order to explore the energetics of this process, we compared the band structures of $\mathrm{VS}_{4}$ with that of $\mathrm{Li}_{3} \mathrm{VS}_{4}$ (Figure SI. 13) by performing calculations using the structure of $\mathrm{K}_{3} \mathrm{VS}_{4}$, replacing $\mathrm{K}^{+}$by $\mathrm{Li}^{+}$(and performing geometry optimizations). The results indicate stabilization of the Fermi energy upon formation of the lithiated intermediate $\mathrm{Li}_{3} \mathrm{VS}_{4}$, giving further evidence that such an internal redox process is energetically favorable. (We note that we are unlikely to have found the ground state $\mathrm{Li}_{3} \mathrm{VS}_{4}$ structure; the relative lowering of the Fermi energy for this structure is likely to be even more pronounced). Such an internal redox process has been observed to occur chemically in vanadium-thiol complexes which contain patronite-like $\mathrm{V}_{2}\left(\mathrm{~S}_{2}\right)_{2}$ units. ${ }^{52}$ Reaction of a $\mathrm{VS}_{4}{ }^{3-}$ solution with tetraisobutylthiuram disulphide results in the formation of a novel vanadium (IV) dimer $\left(\mathrm{V}^{\mathrm{IV}}{ }_{2}\left(\mathrm{~S}_{2}\right)_{2}\left(i-\mathrm{Bu}_{2} \mathrm{NCS}_{2}\right)_{4}\right)$ formed by an induced internal reaction whereby reduction of $\mathrm{V}^{5+}$ is accompanied by oxidation of $\mathrm{S}^{2-}$. The latter complex has a $\mathrm{V}_{2}\left(\mathrm{~S}_{2}\right)_{2}$ structural unit similar to that seen in patronite with a V-V bond having a distance of $2.8 \AA$. This sort of internal electron transfer is facilitated by hybridization of metal $d$ bands with bands belonging to the ligand (in this case $\mathrm{S}_{2}{ }^{2-}$ ) although further band structure calculations of $\mathrm{VS}_{4}$ are needed to confirm this.

Once full reduction to sulfide has occurred, further lithiation occurs which involves reduction of $\mathrm{V}^{5+}$ to $\mathrm{V}^{4+}$ as indicated by the appearance of a paramagnetic feature in the ${ }^{6} \mathrm{Li}$ NMR spectrum at this stage of the discharge profile. However the observation of a ${ }^{51} \mathrm{~V}$ NMR signal at this stage suggests that the intermediate formed at this stage also has some vanadium diamagnetic centers and the shifted ${ }^{51} \mathrm{~V}$ resonance (at $-546 \mathrm{ppm}$ ) is attributed to a mixed valent compound with both $\mathrm{V}(\mathrm{IV})$ and $\mathrm{V}(\mathrm{V})$ centers, $\mathrm{V}(\mathrm{V})$ centers giving rise to the $-546 \mathrm{ppm}$ resonance. Further reduction leads to the formation of fcc $\mathrm{V}$ and $\mathrm{Li}_{2} \mathrm{~S}$. These redox processes are summarized in Figure 11. In contrast to the oxides where redox activity is primarily centered on the transition metal ion, in the sulphides it is observed that extensive covalency of the metal-ligand bond causes redox activity to involve the ligand as well. This has been seen earlier in the thiospinels ${ }^{53}$ for instance, where an interplay between $\mathrm{S}^{2-}$ and $\mathrm{S}_{2}{ }^{2-}$, attributed to hybridization of metal-sulfur orbitals, is observed. The present is a unique case among the sulphides involving oxidation of the cation concomitant with reduction of the anion. A similar chemistry has been proposed with regard to the the Li-rich oxides $\left(\mathrm{Li}_{2} \mathrm{Ru}_{1-}\right.$ ${ }_{y} \mathrm{Sn}_{y} \mathrm{O}_{3}$ ) where reduction of $\mathrm{Ru}^{6+}$ to $\mathrm{Ru}^{5+}$ is accompanied by oxidation of $\mathrm{O}^{2-}$ to $\mathrm{O}_{2}{ }^{2-} \cdot{ }^{54}$

$\mathrm{V}$ metal is in general stable as the bcc polymorph. ${ }^{42}$ However, previous studies of $\mathrm{V}$ nanoparticles formed during ball-millling of $\mathrm{V}$ metal in a nitrogen atmosphere have observed the formation of fcc $\mathrm{V}$, which is formed along with the formation of $\delta$ - VN. ${ }^{55}$ The $\mathrm{V}$ metal formed towards the end of the discharge cycle is similarly nanoparticulate and presumably 
forms with a large number of defects, the former leading to a large surface to volume ratio. Presumably, the fcc form minimizes the surface energies, ${ }^{55}$ which is possibly further facilitated by the occlusion of $\mathrm{C}$ atoms into the structure from the electrolyte.

Upon charging, the resonance at $\sim-565 \mathrm{ppm}$ is indicative of the formation of the lithiated intermediate whose composition is tentatively assumed to be $\mathrm{Li}_{3.5} \mathrm{VS}_{4}$. . Delithiation to form $\mathrm{Li}_{3.5} \mathrm{VS}_{4}$ would yield a charge capacity of $\sim 525 \mathrm{mAh} / \mathrm{g}$. However the capacity observed upon charge is in excess of this, suggesting that further delithiation to form $\mathrm{VS}_{4}$ also occurs. The $\mathrm{S} \mathrm{K}$-edge XANES spectra at the end of charge $(3 \mathrm{~V})$ indicates that a phase similar to $\mathrm{VS}_{4}$ is formed. This phase is clearly amorphous/disordered as no reflections are observed in the diffraction pattern. However, the PDF pattern clearly shows evidence for both $\mathrm{S}_{2}{ }^{2-}$ ions and $\mathrm{V}-\mathrm{S}$ bonds The ${ }^{51} \mathrm{~V}$ NMR signal at $161 \mathrm{ppm}$ characteristic of $\mathrm{VS}_{4}$ is not however observed upon charging, however a very broad signal around this chemical shift range is observed (in addition to the $\sim-565 \mathrm{ppm}$ resonance. This discrepancy can be a consequence of the greater degree of disorder of the $\mathrm{VS}_{4}$ phase formed upon charging. As a result, defects are likely present so that complete spin pairing of all the adjacent $\mathrm{V}$ atoms does not occur leading to the presence of paramagnetic centers and peak broadening.

Reversibility in Li ion batteries is generally contingent upon there being minimal structural reorganization during charging and discharging of the battery. In conversion electrode materials however there is no topochemical structural relationship between the starting material and the product obtained at the end of discharge and extensive bond breaking occurs during the redox process. The large activation energy required for reformation of the starting material contributes to the large voltage hysteresis between discharge and charge cycles. With increasing covalency of the M-X bond, this voltage gap decreases, with fluorides generally exhibiting a larger voltage gap between discharge and charge when compared with sulphides and phosphides. ${ }^{6,47}$ The reaction to form $\mathrm{V}+\mathrm{Li}_{2} \mathrm{~S}$ studied here exhibits a $\Delta \mathrm{E}_{\mathrm{hys}}$ of 1.0 -1.3 V (Figure SI. 14), which is comparable to that of many other sulfide conversion materials. However, as appears increasingly to be the case for many of these systems, ${ }^{56}$ the difference between the structural pathways taken on discharge and charge must also contribute to the hysteresis. The good reversibility in this system is partly attributed to the rGO which forms a conducting pathway over the insulating products formed at the end of discharge.

\section{CONCLUSIONS}

In conclusion, we have used a range of short range characterization techniques (NMR, PDF and XANES) to elucidate the structural transformations occurring during complete reductive lithiation (addition of $8 \mathrm{Li}$ per formula unit) of the Peierls distorted vanadium sulphide, $\mathrm{VS}_{4}$. The studies are complemented by an examination of the DFT electronic structure of $\mathrm{VS}_{4}$. Unlike many of the electrode materials where electron transfer is centered either on the cation or on the anion, here we observe a complex redox interplay involving electron transfer between the cation and the anion leading to the breaking of the S-S dimers of $\mathrm{VS}_{4}$ and the formation of metastable intermediates such as $\mathrm{Li}_{3} \mathrm{VS}_{4}$. This process is found to be partially reversible and is here attributed to extensive metal-ligand covalency in $\mathrm{VS}_{4}$. 


\section{ACKNOWLEDGEMENTS}

SB acknowledges Schlumberger Stichting Fund and European Research Council (EU ERC) for funding. JC thanks BK21 plus project of Korea. We thank Phoebe Allan and Andrew J. Morris, University of Cambridge, for useful discussions. We also thank Trudy Bolin and Tianpin Wu of Beamline 9-BM, Argonne National Laboratory for help with XANES measurements. The DFT calculations were performed at the UCSB Center for Scientific Computing at UC Santa Barbara, supported by the California Nanosystems Institute (NSF CNS-0960316), Hewlett-Packard, and the Materials Research Laboratory (DMR-1121053). This research used resources of the Advanced Photon Source, a U.S. Department of Energy (DOE) Office of Science User Facility operated for the DOE Office of Science by Argonne National Laboratory under Contract No. DE-AC02-06CH11357.

Supporting Information Available:

In-situ X-ray Diffraction data, additional ${ }^{51} \mathrm{~V}$ NMR data, first derivative of the normalized S K-edge XANES spectra as well as absolute DOS of $\mathrm{VS}_{4}$ and $\mathrm{Li}_{3} \mathrm{VS}_{4}$ are provided as Supporting Information. This information is available free of charge via the internet at http://pubs.acs.org.

\section{REFERENCES}

(1) Mizushima, K., Jones, P. C., Wiseman. P. J., Goodenough, J. B. Mater. Res. Bull. 1980, 15, 783-789.

(2) Dahn, J. R.; Zheng, T.; Liu, Y.; Xue, J. S. Science 1995, 270, 590-593.

(3) Kim, Y.; Arumugam, N.; Goodenough, J. B. Chem. Mater. 2008, 2, 470-474.

(4) Masquelier, C.; Padhi, A. K.; Nanjundaswamy, K. S.; Goodenough, J. B. J. Solid State Chem. 1998, 135, 228-234.

(5) Padhi, A.; Nanjundaswamy, K. J. Electrochem. Soc. 1997, 144, 2581-2586.

(6) Cabana, J.; Monconduit, L.; Larcher, D.; Palacin, R. M. Adv. Mater. 2010, 22, E170E192.

(7) Whittingham, M. Prog. Solid State Chem. 1978, 12, 41-99.

(8) Debart, A.; Dupont, L.; Patrice, R.; Tarascon, J.-M. Solid State Sci. 2006, 8, 640-651.

(9) Golodnitsky, D.; Peled, E. Electrochim. Acta. 1999, 45, 335.

(10) Hillebrand, W. F. J. Am. Chem. Soc. 1907, 1019-1029. 
(11) Xu, X.; Jeong, S.; Rout, C. S.; Oh, P.; Ko, M.; Kim, H.; Kim, M. G.; Cao, R.; Shin, H. S.; Cho, J. J. Mater. Chem. A 2014, 2, 10847-10853.

(12) Rout, C. S.; Xu, X.; Yang, J.; Jeong, H. Y.; Odkhuu, D.; Park, N.; Cho, J.; Shin, H. S. J. Am. Chem. Soc. 2013, 135, 8720-8725.

(13) Allmann, R.; Baumann, I.; Kutoglu, A.; Rosch, H.; Hellner, E. Naturwissenschaften 1964, 51, 263

(14) Whangbo M, H and Gressier, P. Inorg. Chem. 1984, 23, 1228-1232

(15) Klemm, W.; Schnering, H. G. Naturwiss. 1965, 52, 12.

(16) Klemm, W.; Hoschek, E. Z. Anorg.u. Allgem. Chem. 1936, 226, 359

(17) Lapina, O. B.; Khabibulin, D. F.; Shubin, A. A.; Terskikh, V. V. Prog. Nucl. Magn. Res. Spec. 2008, 53, 128.

(18) Kresse, G and Hafner, J. Phys. Rev. B 1993, 47, 558-561

(19) Kresse, G and Hafner, J. Phys. Rev. B. 1994, 49, 14251-14269

(20) Kresse, G and Furthmuller, J. Comput. Mat. Sci. 1996, 6, 15-50

(21) Kresse G and Furthmuller, J Phys. Rev. B. 1996, 54, 11169

(22) Blöch P. E Phys. Rev. B. 1994, 50, 17953

(23) Kresse, G and Joubert, D Phys. Rev. B. 1999, 59, 1758

(24) Perdew J. P, Burke, K and Ernzerhof, M. Phys. Rev. Lett. 1996, 77, 3865

(25) Heyd, J.; Scuseria, G. E.; Ernzerhof, M. J. Chem. Phys. 2006, 124, 219906.

(26) Momma, K.; Izumi F, J. Appl. Crystallogr. 2011, 44, 1272-1276.

(27) Kovtyukhova, N. I.; Ollivier, P. J.; Martin, B. R.; Mallouk, T. E.; Chizhik, S. A.; Buzaneva, E. V. Gorchinskiy, A. D. Chem. Mater. 1999, 11, 771

(28) Borkiewicz, O. J.; Shyam, B.; Wiaderek, K. M.; Kurtz, C.; Chupas, P. J.; Chapman, K. W. J. Appl. Cryst. 2012, 45, 1261-69

(29) Hammersley, A., 1998, FIT2D V9.129 reference manual V3.1. ESRF internal report 98HA01T, ESRF.

(30) Qiu, X.; Thompson, J. W.; Billinge, S. L. J. Appl. Cryst. 2004, 37, 678.

(31) Farrow, C. L.; Juhas, P.; Lui, J. W.; Bryndin, E. S.; Bozin, J.; Bloch, T.; Proffen, T.; Billinge, S. J. L., Journal of Physics: Condensed Matter 2007, 19, 335219. 
(32) Sekiyama, H.; Kosugi, N.; Kuroda, H.; Ohta, T. Bull. Chem. Soc. Jpn. 1986, 59, 575

(33) Ravel, B.; Newville, M. J. Synchrotron. Radiation 2005, 12, 537

(34) Grey, C. P.; Dupré, N. Chem. Rev. 2004, 104, 4493.

(35) Meyer, B. M.; Leifer, N.; Sakamoto, S.; Greenbaum, S. G.; Grey, C. P. Electrochem. Solid State Lett. 2005, 8, A145.

(36) Zhang, Y. P.; Holm, R. H. Inorg. Chem. 1988, 27, 3875

(37) Hayden, Y. T.; Edwards, J. O. Inorganica Chim. Acta 1986, 114, 63-69.

(38) Harrison, A. T.; Howarth, O. W. J. Chem. Soc. Dalton Trans. 1986, 1405.

(39) Simonnet-Jégat, C.; Sécheresse, F. Chem. Rev. 2001, 101, 2601-2612.

(40) Rehder, D.; Weidermann, C.; Duch, A.; Priebsch, W. Inorg. Chem. 1988, 27, 584-587

(41) Delmaire, F.; Rigole, M.; Zhilinskaya, E. A.; Aboukais, A.; Hubaut, R.; Mairesse, G. Phys. Chem. Chem. Phys. 2000, 2, 4477-4483

(42) Carlson, O. N.; Owen, C. V. J. Electrochem. Soc. 1960, 107, 69.

(43) Fleet, M. E.; Liu, X.; Harmer, S. L.; King, P. L. Can. Mineral. 2005, 43, 1605-1618

(44) Solomon, E. I.; Hedman, B.; Hodgson, K. O.; Dey, A.; Szilagyi, R. K. Coordn. Chem. Rev. 2005, 249, 97

(45) Yamakawa, N.; Jiang, M.; Key, B.; Grey, C.P. J. Am. Chem. Soc. 2009, 131, 10525

(46) Dambournet, D.; Chapman, K. W.; Chupas, P. J.; Gerald, R. E.; Penin, N.; Labrugere,C.; Demourgues, A.; Tressaud, A.; Amine, K. J. Am. Chem. Soc. 2011, 133, 13240.

(47) Hua, X; Robert, R.; Du, L.-S; Wiaderek, K. M.; Leskes, M.; Chapman, K. W.; Chupas, P. J.; Grey, C. P. J. Phys. Chem. C. 2014, 118, 15169.

(48) Shyam, B.; Chapman, K. W.; Balasubramanian, M.; Klingler, R. J.; Srajer, G.; Chupas, P. J. Angew. Chem. Int. Ed. Engl. 2012, 51, 4852.

(49) Chapman, K. W.; Lapidus, S.; Chupas, P. J. "Applications of Principal Component Analysis to Pair Distribution Function Data", J. Appl. Cryst., submitted.

(50) Nielsen, U. G.; Skibsted, J.; Jakobsen, H. J. Chem. Phys. Lett. 2002, 356, 73.

(51) Smaalen, S. Acta Cryst. A. 2005, A61, 51. 
(52) Halbert, T. R.; Hutchings, L. L.; Rhodes, R.; Steifel, E. I. J. Amer. Chem. Soc. 1986, $108,6437-6438$

(53) Bodenez, V.; Dupont, L.; Morcrette, M.; Surcin, C.; Murphy, D. W.; Tarascon, J. -M. Chem. Mater. 2006, 18, 4278

(54) Sathiya, M.; Rousse, G.; Ramesha, K.; Laisa, C. P.; Vezin, H.; Sougrati, M. T.; Doublet, M.-L.; Foix, D.; Gonbeau, D.; Walker, W.; Prakash, A. S.; Hassine, M. B.; Dupont, $\quad$ L.; Tarascon, J.-M. Nature Materials, 2013, 12, 827.

(55) Lopez-Flores, V.; Roldan, M. A.; Real, C.; Paez, A. M.; Castro, G. R. J. Appl. Phys. 2008, 104, 023519.

(56) Yu, H-C.; Ling, C.; Bhattacharya, J.; Thomas, J. C.; Thornton, K.; Van der Ven, A.; Energy Environ. Sci. 2014, 7, 1760. 
Table of Contents Figure

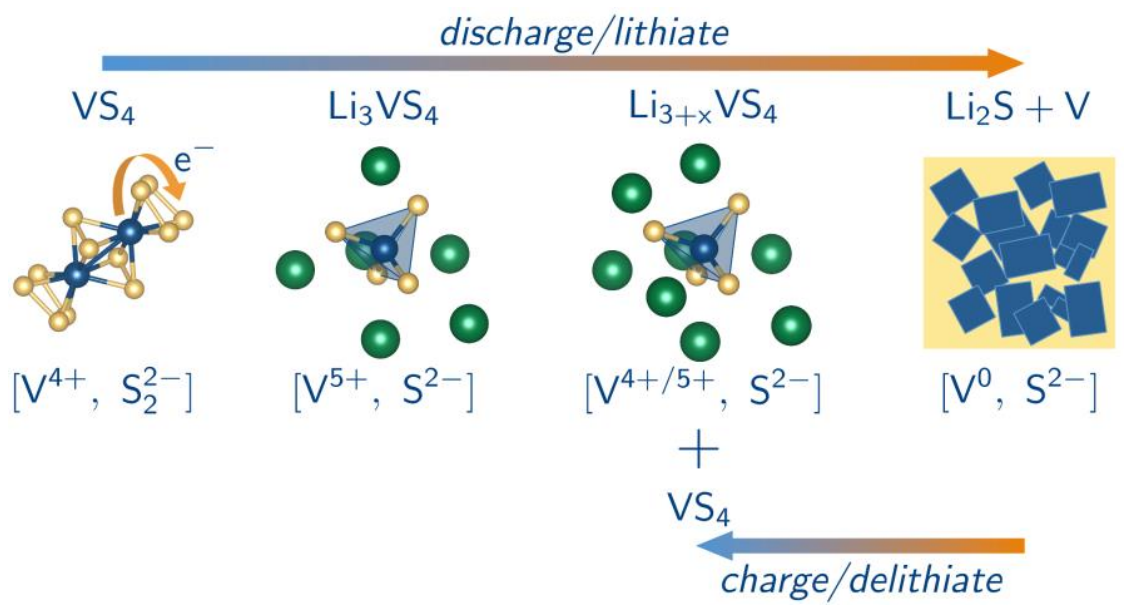

Figures 
(a) dimerized

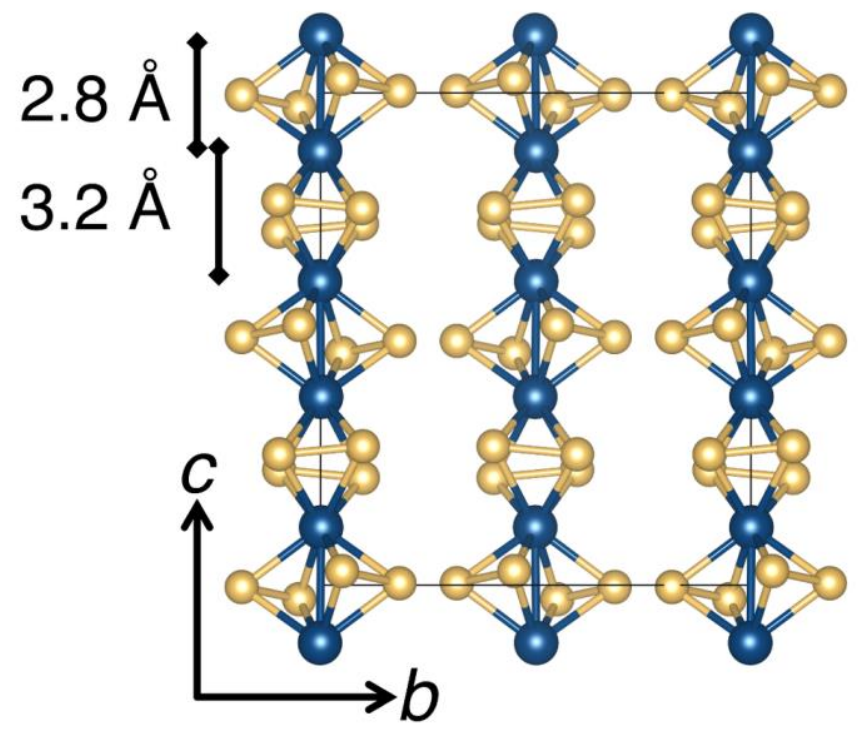

(b) undistorted

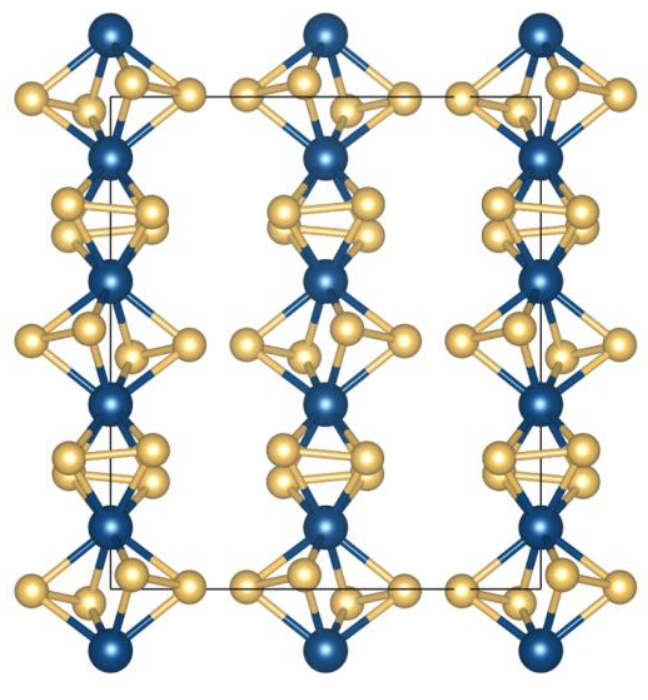

Figure 1. Structure of (a) dimerized, Peierls distorted $\mathrm{VS}_{4}$ and (b) an undistorted version, projected down the $a$ axis. 
(a)

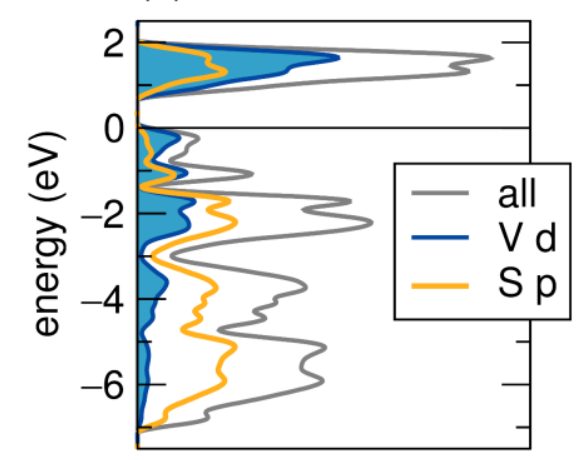

(b)

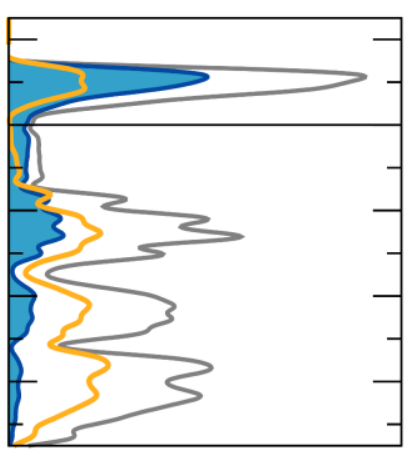

DOS (states $\mathrm{eV}^{-1}$ cell $^{-1}$ )

(c)

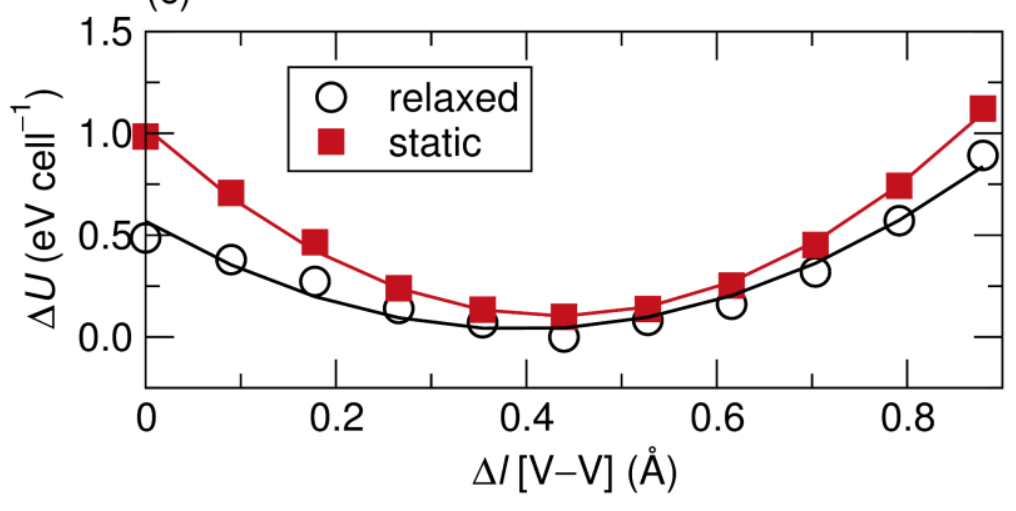

Figure 2. Densities of states (DOS) for (a) Peierls-distorted $\mathrm{VS}_{4}$ and (b) its undistorted variant, showing that the distortion opens an insulating gap in the densities of state. (c) Energetic stabilization per unit cell arising from the Peierls distortion, depicted as a function of the bond alternation, the difference in length between the short and long $\mathrm{V}-\mathrm{V}$ distances along the $c$ direction. 


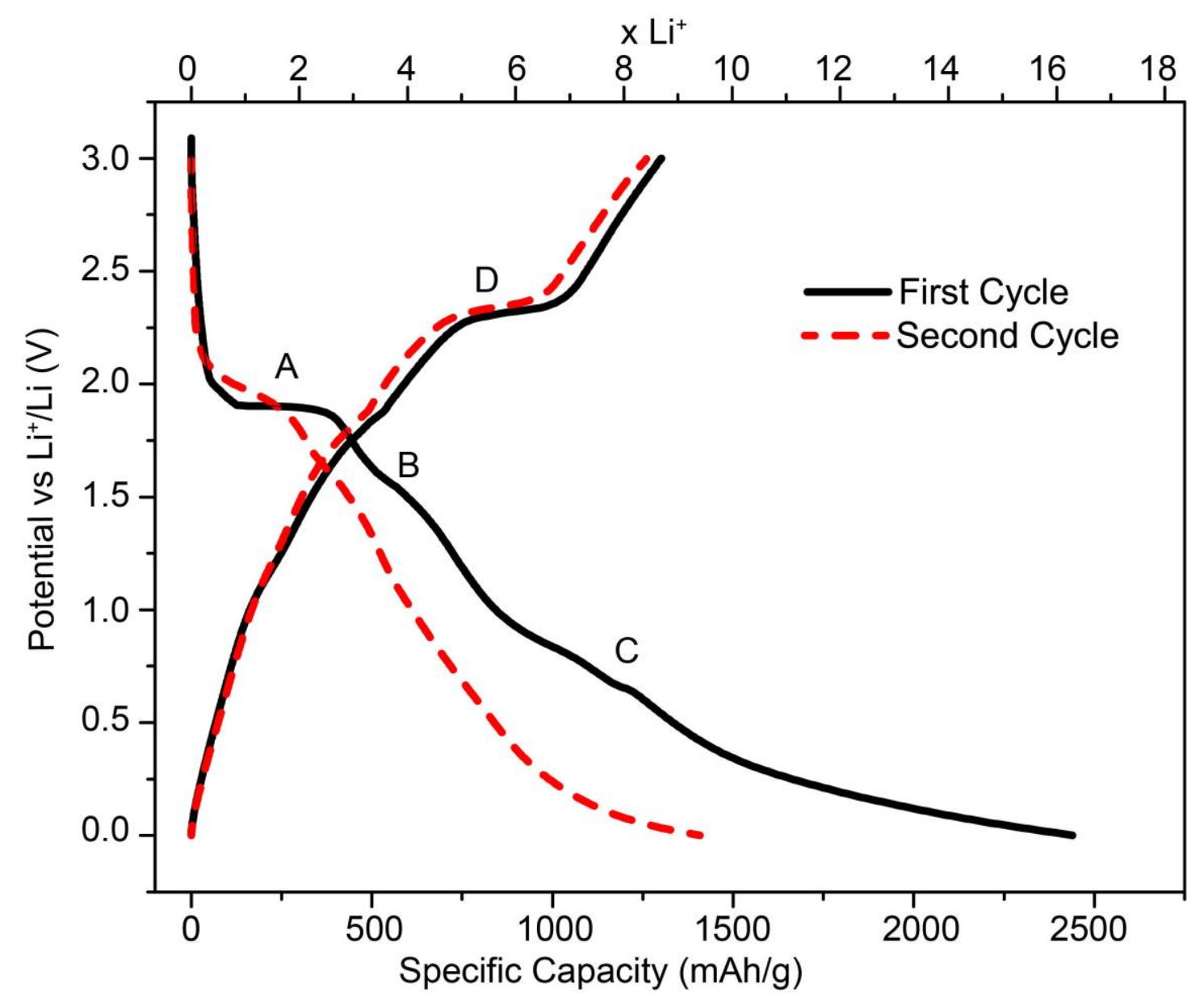

Figure 3. Galvanostatic charge-discharge curve of $\mathrm{VS}_{4}-\mathrm{rGO}$ cycled between 0.0 and $3.0 \mathrm{~V}$ at a rate of $\mathrm{C} / 10$. The first two cycles are shown. A, B, C and D correspond to the more pronounced processes that are described in the text. 


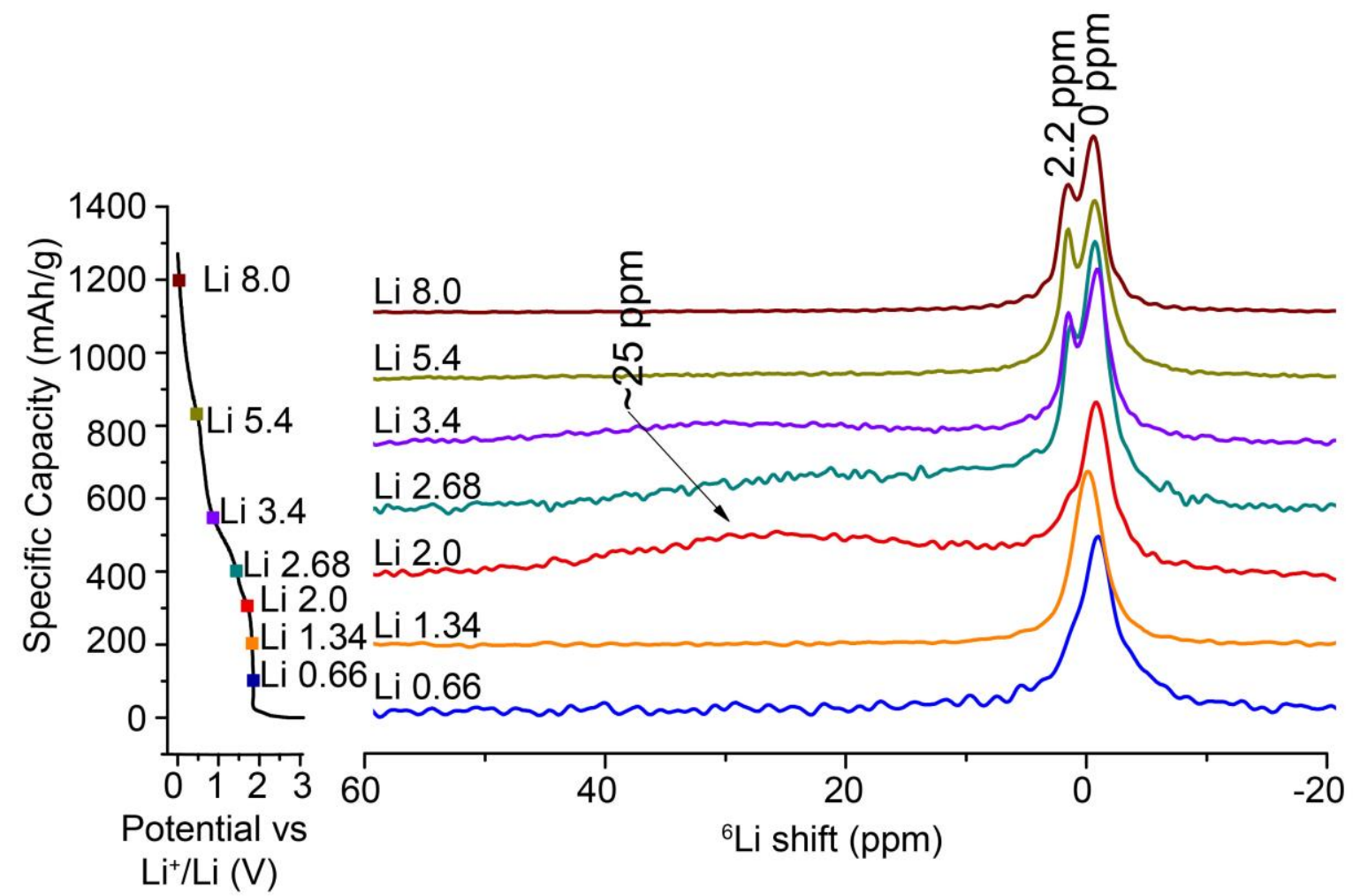

Figure 4. ${ }^{6} \mathrm{Li}$ MAS NMR spectra of discharged $\mathrm{VS}_{4}-\mathrm{rGO}$ samples between $\mathrm{Li}=0.66-8.0$, acquired at a field strength of $7.05 \mathrm{~T}$. The intensities were normalized with number of scans and weight of sample. 

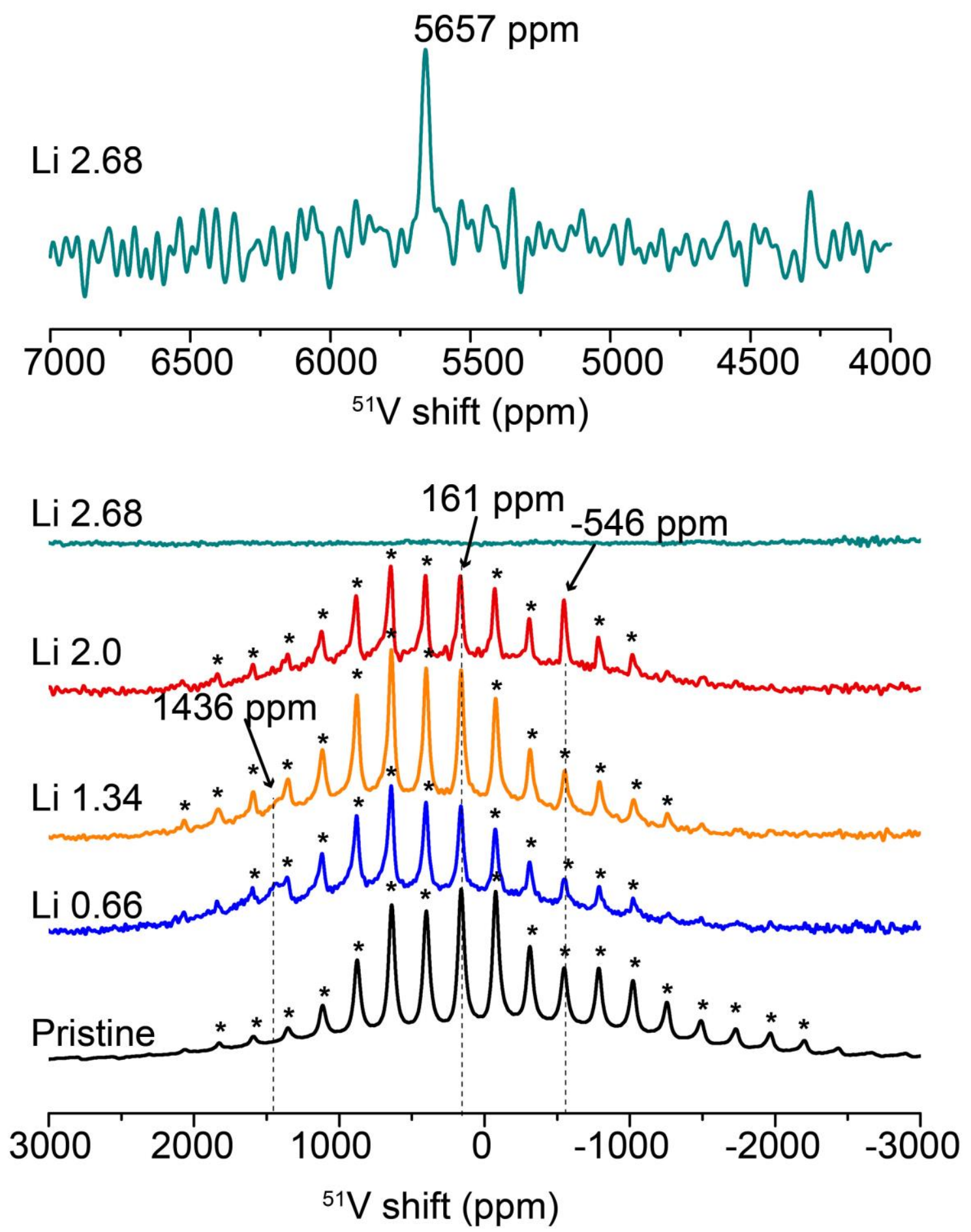

Figure 5. ${ }^{51} \mathrm{~V}$ NMR spectra of $\mathrm{VS}_{4}$-rGO acquired at $9.4 \mathrm{~T}$ during the first discharge curve for Li 0.66 - Li 2.68. The electrochemistry is as shown in Figure 4. The isotropic shifts are determined by measuring the spectra at two different spinning speeds (see supplemental figure, SI. 5) and are indicated by their isotropic shifts and dashed lines. The asterisks denote spinning side bands. The pristine spectrum was acquired at a different carrier frequency $(\mathrm{O} 1)$ of $\sim-565 \mathrm{ppm}$ compared to the other spectra ( 200 ppm). 


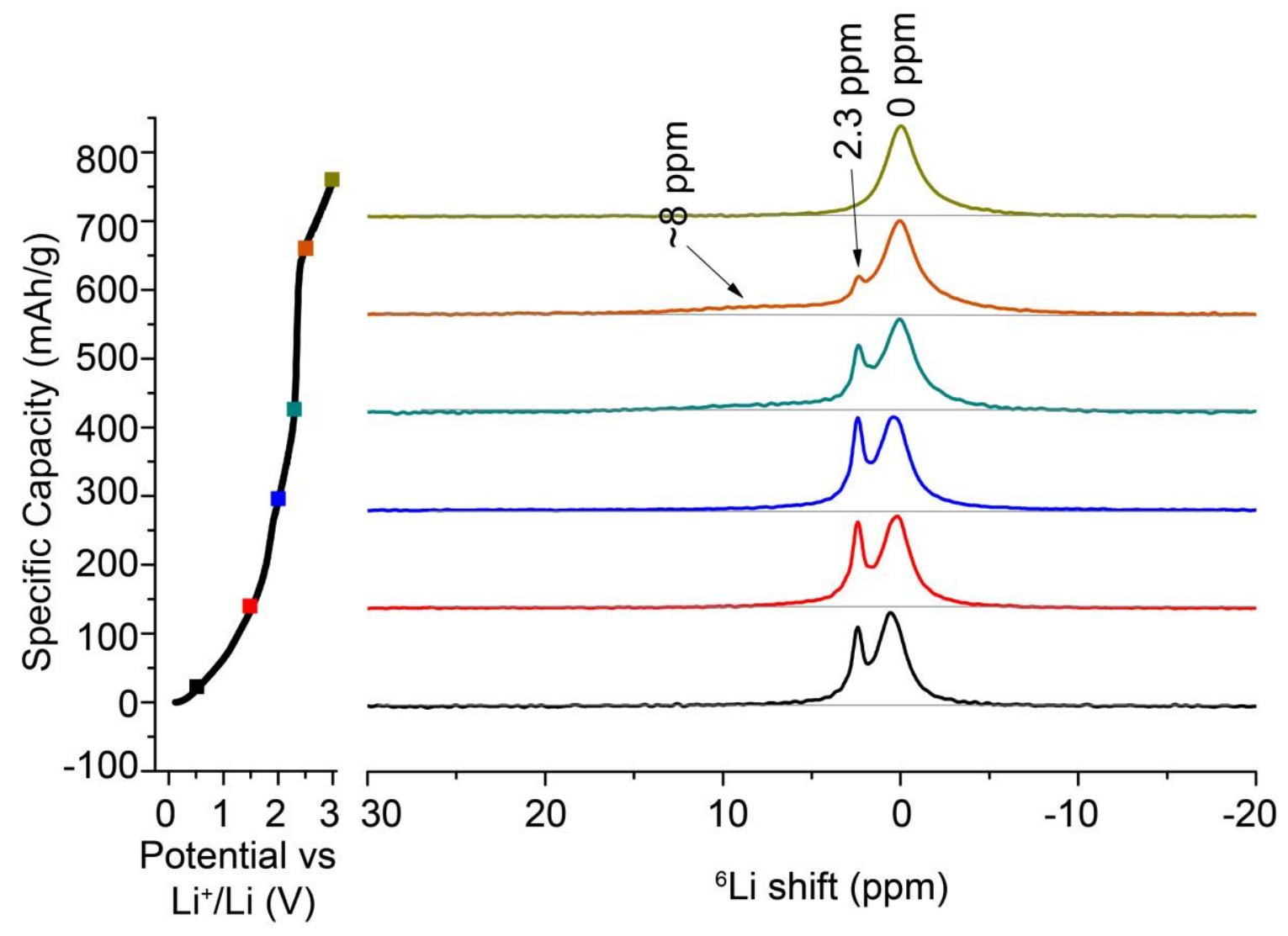

Figure 6. ${ }^{6} \mathrm{Li} \mathrm{NMR}$ spectra of $\mathrm{VS}_{4}-\mathrm{GO}$ during charge. The dashed baseline is shown so that the broader resonance at $\sim 8 \mathrm{ppm}$ can be seen more clearly. 

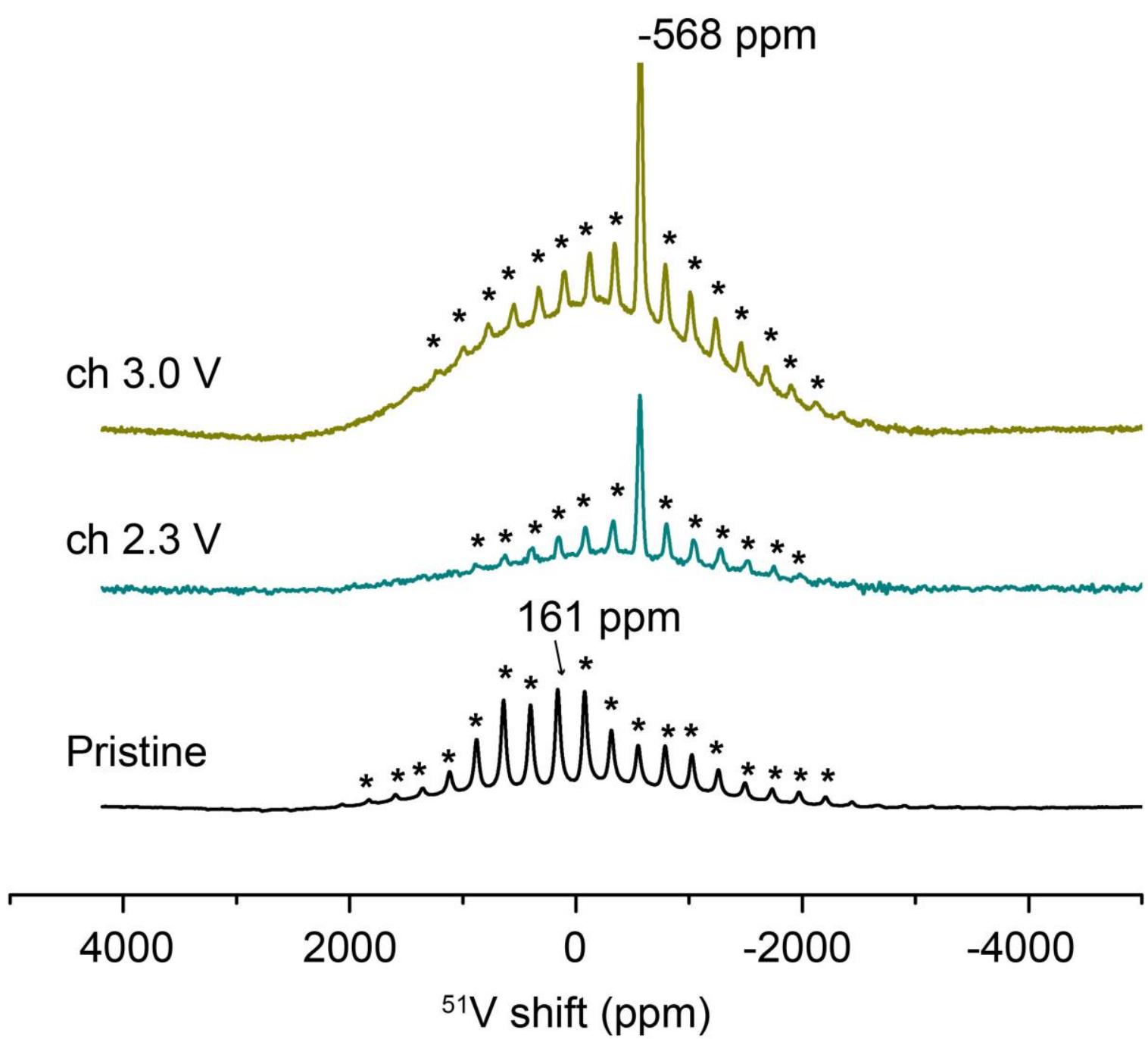

Figure 7. ${ }^{51} \mathrm{~V}$ NMR of samples acquired during charging, acquired at $9.4 \mathrm{~T}$. The resonance at $-568 \mathrm{ppm}$ has been truncated to show the lower intensity resonances more clearly. 


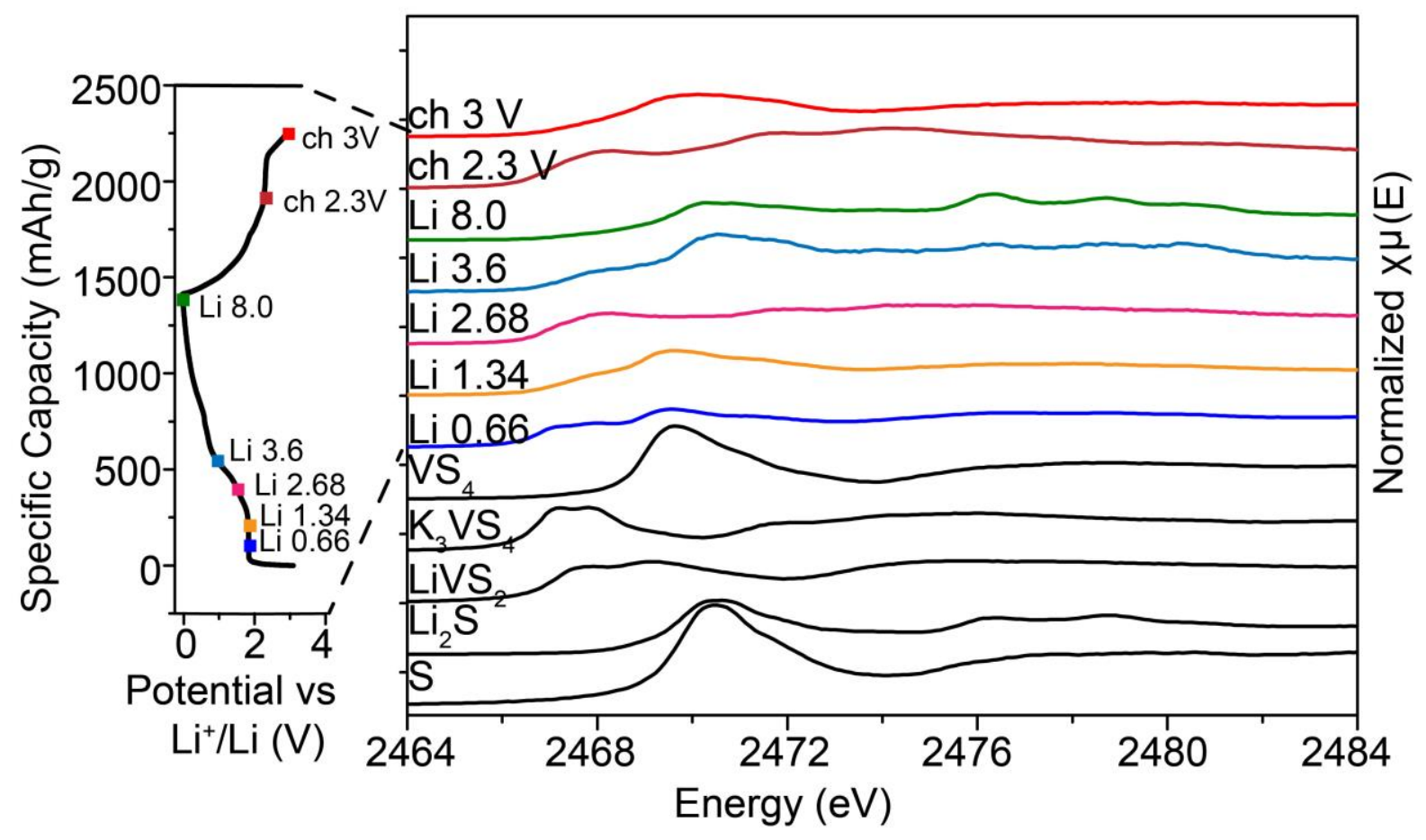

Figure 8. Normalized S K-edge XANES spectra of the model compounds and cycled $\mathrm{VS}_{4^{-}}$ rGO samples. 


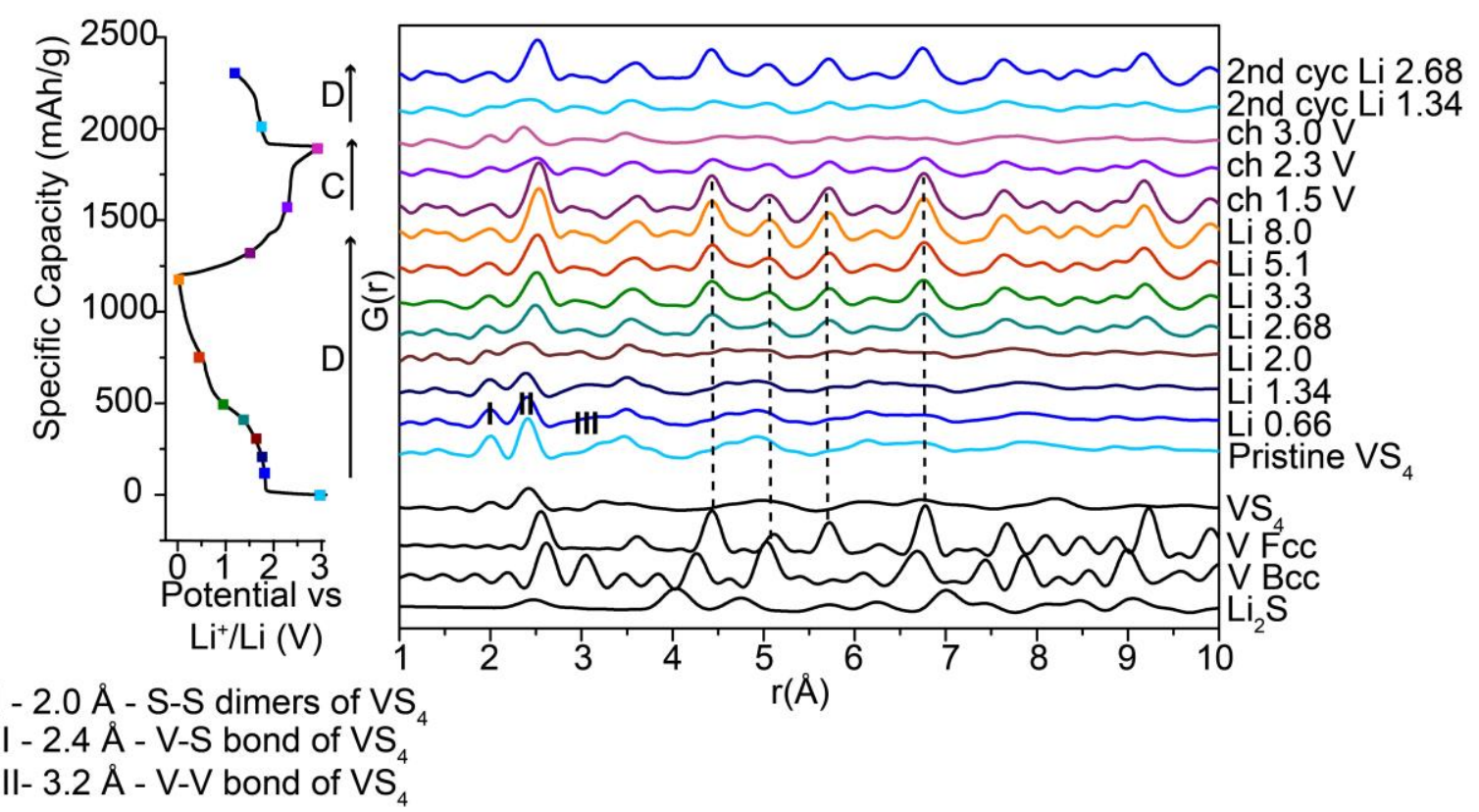

Figure 9. Ex-situ Pair Distribution Function data of $\mathrm{VS}_{4}-\mathrm{rGO}$ samples. The simulated PDF patterns of the model compounds $\left(\mathrm{VS}_{4}, \mathrm{Li}_{2} \mathrm{~S}\right.$, bcc and fcc $\left.\mathrm{V}\right)$ are given at the bottom. The vertical lines correspond to fcc-V
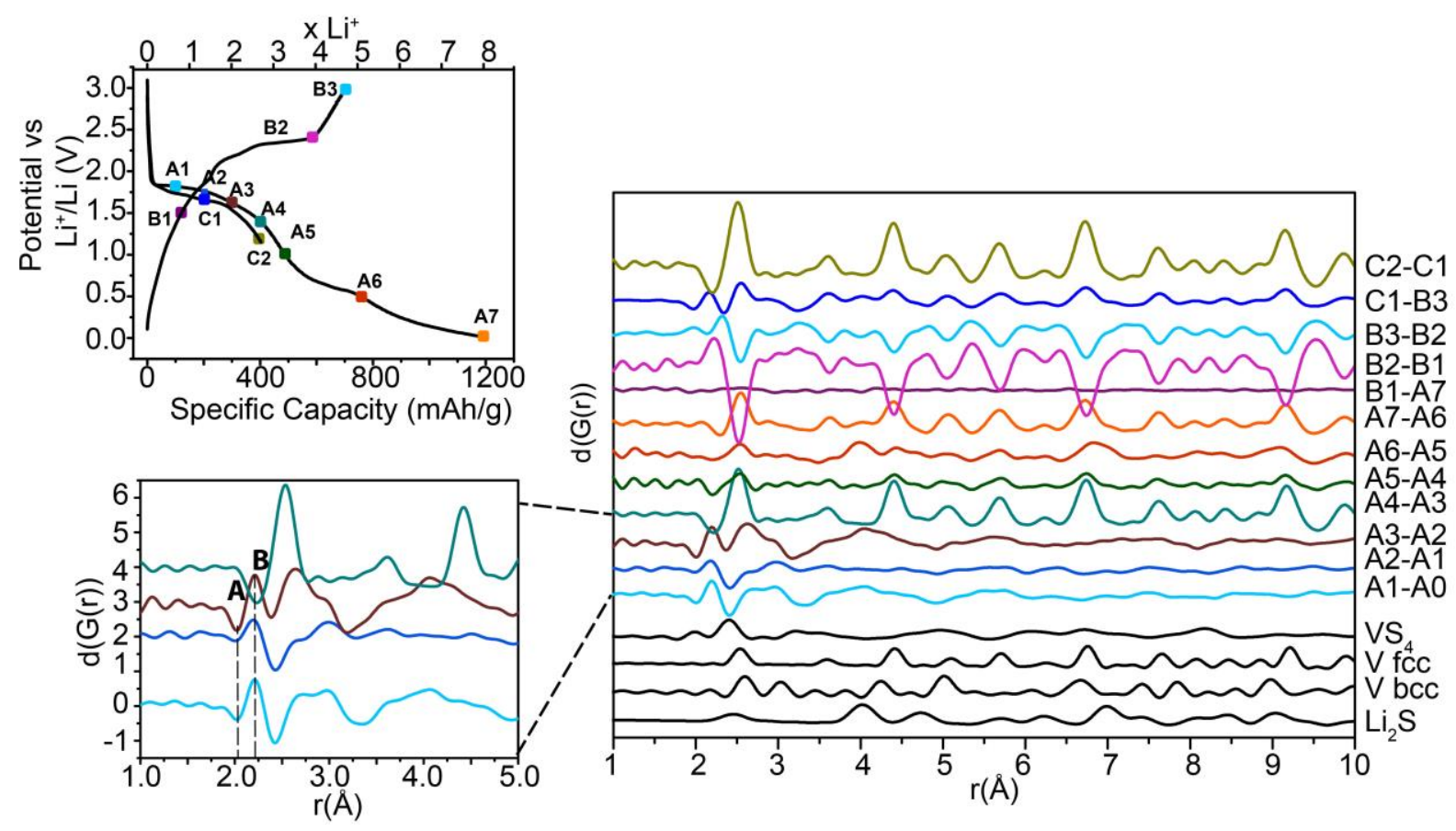

Figure 10. Ex-situ Difference PDF patterns of $\mathrm{VS}_{4}-\mathrm{rGO}$. A and B in the left lower side panel are referred to in the text. 


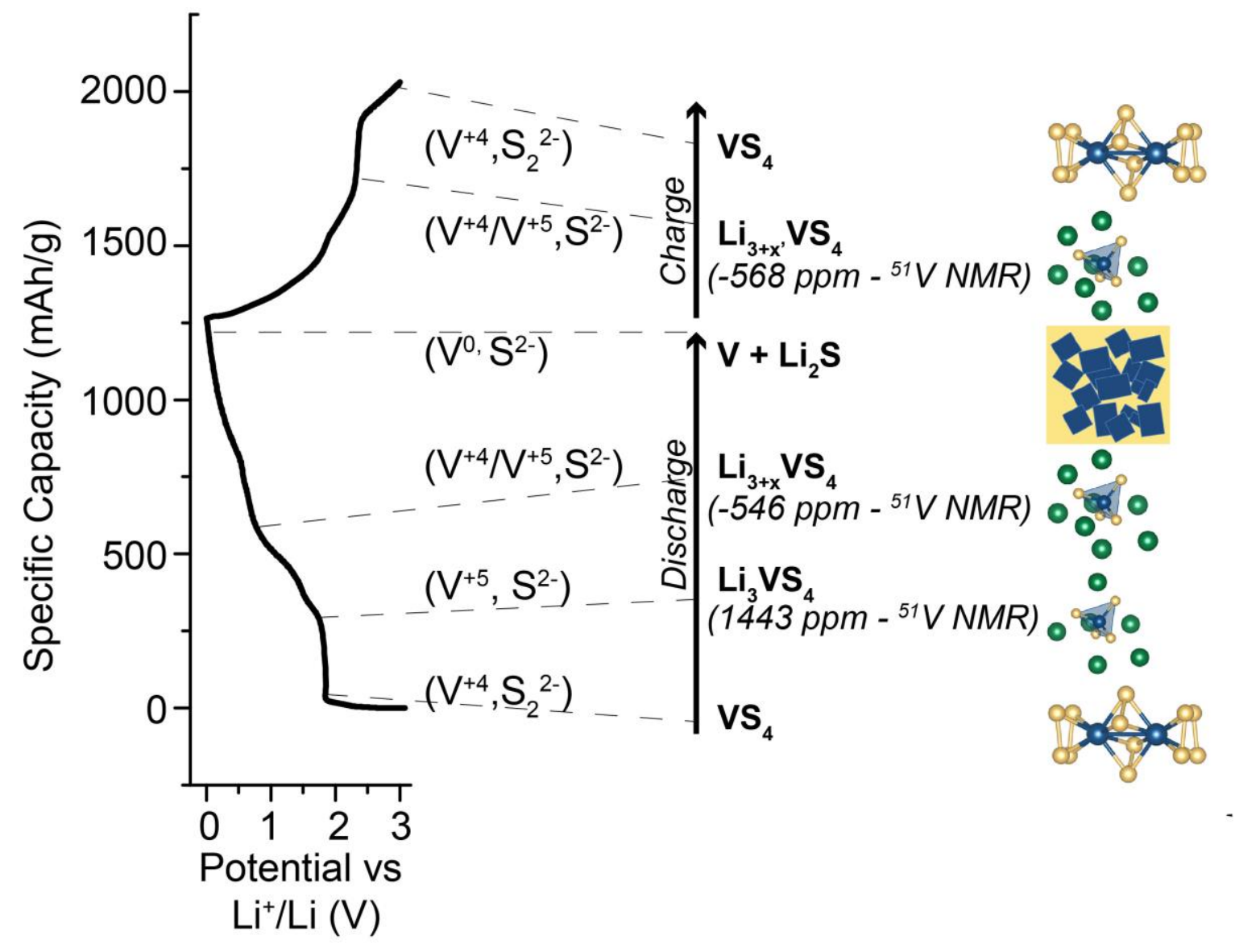

Figure 11. Summary of the redox processes occurring during discharge/charge of $\mathrm{VS}_{4}$. 